\title{
KNOWLEDGE ABOUT LEGAL SANCTIONS
}

\author{
Stephen McG. Bundy* \\ and Einer Elhauge**
}

For a system that likes to say that ignorance of its rules is no excuse, the legal system can be remarkably ambivalent about whether the dissemination of knowledge about those rules is good or bad. Lawyers have, in particular, been roundly condemned for providing truthful information about the law that helps clients avoid punishment for wrongdoing, exploit loopholes to engage in legal but undesirable activity, recognize illegal activities that have low penalties or chances of detection, and do better in litigation than they should have. ${ }^{1}$ Ignorance of the law may be no excuse, but too much knowledge of the law is, apparently, no virtue.

Often, however, knowledge or advice about the law is undeniably desirable. How, then, do we sort out the good from the bad? The legal profession's answer, at least as reflected in its rules governing the provision of advice to a client, has been to presume that advice is strongly desirable. Traditionally those rules have required lawyers to provide their clients with complete and accurate advice about the law and the legal system, unless the lawyer knows that the advice will simply further criminal or fraudulent conduct. ${ }^{2}$

Many observers believe that this approach allows lawyers to give far too much undesirable advice. One responsive intuition has been to distinguish between functional categories of advice: for example, between advice that alters legal penalties (or sanctions) for a given

* Professor, School of Law (Boalt Hall), University of California at Berkeley. B.A. 1973, Harvard; J.D. 1978, University of California at Berkeley.-Ed.

** Professor, School of Law (Boalt Hall), University of California at Berkeley. Visiting Olin Faculty Fellow, Yale Law School. B.A. 1982, J.D. 1986, Harvard.-Ed. The authors would like to thank Meir Dan-Cohen, Geoffrey Hazard, Susan Koniak, Richard Lempert, John Leubsdorf, Dan Rubinfeld, David Wilkins, and participants in the law-and-economics workshop at the University of Chicago for helpful comments on earlier drafts, and the John M. Olin Foundation and the Boalt Hall Fund for financial support.

1. See, e.g., Jerome Frank, Courts on Trial: Myth and Reality in American JusTICE 80-87 (1949) (describing lawyers' tactics); MARvin Frankel, PARTISAN JUSTICE 21-38 (1980) (same); William H. Simon, Ethical Discretion in Lawyering, 101 HARV. L. ReV. 1083, 1085 (1988) (same).

2. Under the Model Rules of Professional Conduct (1992), this basic result flows from Rule 2.1 ("[A] lawyer shall ... render candid advice.") and Rule 1.2(d) ("A lawyer shall not counsel a client to engage, or assist a client, in conduct that the lawyer knows is criminal or fraudulent ....") See also Model Rules of Professional Conduct Rules 3.3, 3.4 (1992) (applying similar standards to litigation conduct). 
course of conduct and advice that informs clients about the scope and level of conduct sanctions. ${ }^{3}$ This perspective views litigation advice as obstructionist, helping many individuals avoid sanctions for their past conduct. It regards legal counseling more favorably because it helps individuals conform their future conduct to the law.

This perspective has recently found more structured support in a series of leading articles by Louis Kaplow and Steven Shavell, which offer economic models purporting to demonstrate a "sharp contrast" between the social desirability of legal advice given before actors engage in primary conduct and legal advice during litigation. ${ }^{4}$ If the applicable legal sanctions are appropriately set, they argue, legal advice given to parties planning primary conduct will communicate those sanctions and improve behavior. In contrast, they conclude that legal advice during litigation is as likely to increase as to decrease the information reaching tribunals about past conduct and therefore has "questionable social value."s Accordingly, they put forth (without quite advocating) various proposals that would in effect restrict litigation advice. ${ }^{6}$

Another influential account, however, takes a precisely opposite categorical approach, arguing that, while lawyers should be free to provide advice in litigation consistent with generally accepted partisan norms, a more restrictive standard should govern the provision of prelitigation advice. The first and most famous proponent of this view was Lon Fuller, who strongly defended traditional standards gov-

3. This line has similarities to what William Simon has described as the regulatory approach to legal ethics. See Simon, supra note 1, at 1085-87.

4. See Louis Kaplow \& Steven Shavell, Legal Advice About Information To Present in Litigation: Its Effects and Social Desirability, 102 HARV. L. REv. 567, 597, 600, 614 (1989) [hereinafter Kaplow \& Shavell, Legal Advice About Information]; Steven Shavell, Legal Advice About Contemplated Acts: The Decisions To Obtain Advice, Its Social Desirability, and Protection of Confidentiality, 17 J. LEgal STuD. 123 (1988) [hereinafter Shavell, Legal Advice About Contemplated Acts]; see also Louis Kaplow \& Steven Shavell, Legal Advice About Acts Already Committed, 10 INTL. REV. L. \& ECON. 149, 158 (1990) [hereinafter Kaplow \& Shavell, Legal Advice About Acts Already Committed] (drawing same distinction between advice provided before and after conduct). Shavell draws another sharp distinction between advice that informs parties about the scope or level of expected sanctions and advice that helps parties lower expected sanctions. Shavell, supra, at 136-39.

5. See Kaplow \& Shavell, Legal Advice About Acts Already Committed, supra note 4, at 152; Kaplow \& Shavell, Legal Advice About Information, supra note 4, at 568-69, 597, 614.

6. See Kaplow \& Shavell, Legal Advice About Information, supra note 4, at 611-13 (proposing narrowing confidentiality for litigation advice, requiring litigators to work for the state, or not allowing a party to obtain litigation advice until they have been deposed); see also LLOYD L. WEINREB, DENIAL OF JUSTICE 147-64 (1977) (proposing judicial questioning of criminal defendants before they consult with their lawyers); Marvin E. Frankel, The Search for Truth: An Umpireal View, 123 U. PA. L. REV. 1031, 1055-57 (1975) (proposing a disclosure requirement as long as no privilege is breached). Such proposals would effectively restrict the dissemination of accurate knowledge about litigation sanctions by creating disincentives for the client to ask for it or for the attorney to provide it, or by directly barring such dissemination until after depositions. 
erning the provision of legal advice in litigation but argued that in counseling professional norms should not "grant any license to the lawyer to participate as legal advisor in a line of conduct that is immoral, unfair, or of doubtful legality."7 The view that different and stricter standards should govern the provision of nonlitigation advice retains wide support today. ${ }^{8}$

An alternative line of analysis, most prominently developed by William Simon, rejects both the above categorical approaches in favor of a case-by-case approach. This line recognizes that advice of all forms can contribute to undesirable consequences. Accordingly, Simon concludes that lawyers should deny advice - that is, refuse to disseminate accurate information about the law - in any setting in which such advice would not "promote justice." Simon, indeed, argues that the professional code should not only allow, but require, lawyers to exercise their discretionary judgment to deny advice in such circumstances, with the possible exception of situations in which such a professional canon would not be practically enforceable. ${ }^{10}$ To the extent such professional canons are to have meaningful effects on client behavior, which is their intent, they must effectively deny clients access to truthful information about the law when it would lead to undesirable consequences.

Recent developments in the regulation of lawyers demonstrate that these categorical and noncategorical views have much more than theoretical interest. For example, the 1983 amendments to Rule 11 of the

7. Lon L. Fuller \& John D. Randall, Professional Responsibility: Report of the Joint Conference, 44 A.B.A. J. 1159, 1161 (1958). Given Fuller's evocative but vague formulation of the limits on partisan advocacy, it is unclear whether he would have endorsed every detail of conventional advocacy norms. See id. (arguing that norms of partisanship should forbid an advocate before a tribunal from seeking to "muddy the headwaters of decision"). But it is undeniable that in his conception advocates should have substantially more freedom than counselors to provide advice and assistance.

8. See David B. Wilkins, Making Context Count: Regulating Lawyers After Kaye, Scholer, 66 S. CAL. L. REv. 1145, 1183 (1993) ("The ethical constraints on the actions a lawyer can take on behalf of a client in an adversary proceeding are, and ought to be, different from the constraints on a lawyer acting outside this context."); see also id. at 1183-85 (describing and defending the distinction, and citing other scholars who support it).

9. Simon, supra note 1, at 1089-90; see also DAvid LUBAN, LAwYERS AND JUSTICE: AN ETHICAL STUDY 160-61 (1988) (maintaining that lawyers should "dissociate themselves from projects that are immoral"). Simon divides his general thesis into two subtheses: (1) that lawyers should deny advice when the merits of a potential client's claims and goals are low relative to other potential clients, Simon, supra note 1, at 1091-96; and (2) that lawyers should endeavor "to achieve the most appropriate resolution in each case." Id. at 1096, 1096-113.

10. Simon, supra note 1, at 1084, 1132-33; see also id. at 1094, 1096 (stating that the law firm has a "professional duty" to consider the relative merits of cases before taking them and that his approach "requires" lawyers to try to reach the best result in each case). David Luban states that he "has no objection" to incorporating such a requirement into professional canons but ultimately declines to decide "whether a rule should require or merely permit a lawyer to forego morally objectionable tactics." LUBAN, supra note 9, at 158. 
Federal Rules of Civil Procedure move beyond the "knowing assistance" framework to permit imposition of sanctions on a lawyer who innocently files an action wholly lacking in merit if reasonable prefiling inquiry would have disclosed that lack of merit. ${ }^{11}$ This modification clearly moves the standard for providing litigation advice closer to the sort of contextual judgment envisioned by Simon.

More recently, the highly publicized series of enforcement proceedings brought by the Office of Thrift Supervision against the Kaye, Scholer law firm featured versions of both categorical and situational approaches. Thus, the Office of Thrift Supervision took the position that lawyers giving compliance advice to federally chartered savings and loans should practice the "whole law." This doctrine requires lawyers to investigate client activities that appear to be of doubtful legality and to refuse advice that would frustrate the purposes of regulation even when there is a serious technical argument that the client's conduct is not sanctionable. ${ }^{12}$ Each of these requirements represents an important step toward a contextual duty to deny advice. Kaye, Scholer's abortive defense, in contrast, relied heavily on a categorical distinction between litigation and nonlitigation advice. Because it had been retained solely as litigation counsel, Kaye, Scholer argued, it was wholly inappropriate, as a matter of both precedent and policy, to apply any ethical standard more demanding than the normal prohibition on the presentation of frivolous or knowingly false legal and factual claims. ${ }^{13}$

Although generally limited to legal advice, the above analyses and regulatory proposals bear on a more fundamental question: whether and when knowledge about legal sanctions is desirable. They can thus be linked to what might seem an unrelated line of reasoning: Meir Dan-Cohen's pathbreaking jurisprudential analysis of "acoustic separation" in criminal law. ${ }^{14}$ According to Dan-Cohen, criminal law often transmits "conduct rules" to the public that are harsher than the

11. FED. R. CIV. P. 11. The former rule permitted the imposition of sanctions solely on a showing of subjective "bad faith" See FED. R. CIV. P. 11 advisory committee notes (1983 amendments). The new proposed amendments to the rule retain the rule of reason standard. See FED. R. CIV. P. 11 (proposed amendments).

12. See Advice on How To Exploit Ethical Loopholes May Be Unethical, OTS' Weinstein Says, 56 BNA Banking Rep. (BNA) 616, 616 (Apr. 1, 1991) (reporting remarks of the General Counsel of OTS), available in LEXIS, BNA Library, BNABNK File.

13. Memorandum from Kaye, Scholer Executive Committee to All Kaye, Scholer Personnel (Mar. 2, 1992), cited in Wilkins, supra note 8, at 1148 \& n.4, 1156 [hereinafter Memorandum].

14. See Meir Dan-Cohen, Decision Rules and Conduct Rules: On Acoustic Separation in Criminal Law, 97 HaRv. L. Rev. 625 (1984). We stress that Dan-Cohen would not himself view the topics of legal advice and acoustic separation as unrelated. Id. at 677 \& n.148 (noting his decision to leave unexplored the "complex and crucial role played by lawyers in regard to acoustic separation"). 
actual "decision rules" used to adjudicate cases. This "selective transmission," which can only work under conditions of partial "acoustic separation" between what adjudicators say and what the public hears, prevents individuals from accurately assessing true legal sanctions. But, Dan-Cohen demonstrates, such selective transmission can discourage bad behavior (because individuals think the law is harsh) without producing the actual injustice that might arise from imposing harsh legal standards.

Ironically, the dictum that "ignorance of the law is no excuse" itself illustrates selective transmission because, despite the widespread dissemination of this maxim to the public, ignorance of the law often is a permissible defense in actual adjudication. ${ }^{15}$ The divergence between the maxim and reality is a form of selective transmission that encourages individuals to learn the law, which improves their behavior, but avoids any injustice that would arise from punishing uninformed individuals for conduct they reasonably believed was lawful.

Although Dan-Cohen does not extend his analysis beyond the selective transmission of substantive criminal law defenses and limitations, it can readily be extended to other criminal law issues and to civil law as well. Moreover, although Dan-Cohen does not discuss curbs on legal advice as such, such curbs could, within his framework, be regarded as a strategy of selective transmission. Indeed, because legal advice tends to eliminate acoustic separation, such restrictions may often be essential to implementing any selective transmission strategy. But Dan-Cohen's analysis reminds us that restricting legal advice is only one of many methods by which the legal regime might try to diminish the legal knowledge possessed by the general public.

Against the backdrop of these analyses, we aim to offer a more systematic account of whether and when knowledge about legal sanctions, and restrictions on the dissemination or use of such knowledge, are socially desirable. Because it bears critically on our conclusions, we begin in Part I by developing the point that, even in an optimal sanctioning regime, sanctions are inevitably imprecise. Moreover, this imprecision takes multiple forms involving similar trade-offs. The scope of conduct subject to sanctions will necessarily be over- and underinclusive, including some desirable behavior while failing to include some undesirable behavior. And the level of sanctions will necessarily result in some overdeterrence of desirable behavior and some underdeterrence of undesirable behavior.

Accordingly, even when sanctions are optimal, accurate advice 
about legal sanctions has many adverse effects. However, we conclude in Part II that, absent a skewed distribution of legal ignorance, the overall behavioral consequences of advice about sanctions will tend to be desirable if society has set sanctions to optimize behavior. We also conclude that this proposition applies just as readily to advice about sanctions for litigation conduct as to advice about sanctions for primary conduct. In reaching these conclusions, we reject various categorical distinctions developed in Shavell's analysis of primary conduct advice. We also reject any categorical distinction between the social desirability of advice given prior to litigation and that given during litigation, whether that distinction favors advice about primary conduct, as in the work of Kaplow and Shavell, or litigation advice, as in the work of Fuller and his followers.

We then apply our analysis in Part III to the question whether a noncategorical or case-by-case approach should be used to restrict "undesirable advice" - that is, advice that, in the given situation, will lead to undesirable results. We conclude that fairness arguments might sometimes justify legal advice about sanctions even where such advice has adverse behavioral consequences. More fundamentally, we conclude that Simon's noncategorical approach fails to recognize that, like any other rule, a rule banning undesirable advice will raise overdeterrence problems. Because resolution of whether advice was undesirable will often be inaccurate, such a ban will deter lawyers from giving some advice that would have had desirable results. Moreover, this overdeterrence is likely to be especially severe for clients who are poor, unsophisticated, or have one-shot or low-stakes claims. The total mix of over- and underdeterrence might well be worse than under a categorical approach.

Nor is the question necessarily different in kind if Simon's proposed rule is taken to define only a social or ethical norm without legal force. Although detection and application may well be easier under a social or ethical norm, it will never be perfect, and whatever means are used to resolve questions about the norm's application will also be susceptible to error and, via social sanctions or the internalization of moral norms, over- and underdeterrence. Further, we show that, through the crime-fraud exception, current law actually uses a noncategorical metastandard to trigger either a categorical or noncategorical approach. Such a triggering approach, we argue, can optimize overand underdeterrence better than any unitary rule or standard could.

Finally, we use our analysis in Part IV to generalize and extend Dan-Cohen's analysis to a more global issue: whether and when the law should restrict the dissemination of legal knowledge, whether by 
restricting legal advice or through other means, based on the topic of the knowledge communicated. Under some circumstances, such selective transmission about imperfect sanctions may lead to desirable behavior. But, even when sanctions are nonoptimal, selective transmission can also produce undesirable behavior. We identify the circumstances that will make selective transmission behaviorally desirable or undesirable. We further argue that, given these circumstances, no grounds exist to conclude that advice or knowledge about legal sanctions is in general behaviorally undesirable even when sanctions, if fully known, would not optimize behavior. The desirability of such advice depends instead on evidence about what particular overor underestimations of legal sanctions unadvised or ignorant parties would make given the topic at hand. Moreover, many selective transmission strategies are subject to serious fairness objections. When, as often, selective transmission has ambiguous behavioral effects, fairness concerns will normally dictate rejecting such strategies. Even when selective transmission clearly improves behavior, fairness objections will in some cases provide a basis for forgoing the strategy.

\section{The Unavoidable Trade-OfF in Optimal Legal SANCTIONS}

Legal sanctions are inevitably imperfect. This, by itself, may seem obvious. Perfection is not to be had by mere mortals. And perhaps it is found less often in law than in other human endeavors. But the point here is deeper. Even behaviorally optimal sanctions will be imprecise because punishing (and thus deterring) undesirable behavior can only be accomplished at the price of punishing (and thus deterring) some desirable behavior. At some point, efforts to ameliorate the underpunishment (and underdeterrence) of undesirable behavior will raise the punishment (and overdeterrence) of desirable behavior to unacceptable levels. Hence, behaviorally optimal sanction regimes can, even in theory, achieve no greater perfection than reaching the optimal trade-off between the underdeterrence of undesirable behavior and the overdeterrence of desirable behavior.

Sanctioning regimes can be expected to pursue multiple strategies to achieve this behavioral optimization. Adjusting the level of sanctions is one strategy; adjusting the burden of proof or the scope of sanctionable conduct are other strategies. The pursuit of these multiple strategies means that we cannot assume that the communication of accurate information about the probability and magnitude of even optimal sanctions will improve behavior. Nor can we assume that all legal (or unsanctionable) conduct is desirable under an optimal regime 
or that lowering the actual level of optimal sanctions (for past or contemplated conduct) is undesirable.

All of this deserves particular emphasis here because leading analyses of legal advice have adopted contrary premises. In his seminal economic analysis of legal counseling, for example, Shavell assumed that all unsanctionable conduct is desirable; further, he indirectly assumed that a regime of appropriate sanctions would deter all undesirable conduct but never deter desirable conduct. ${ }^{16}$ In later writings, Kaplow and Shavell used this assumed baseline of appropriate sanctions to draw their sharp contrast between legal counseling advice and litigation advice. ${ }^{17}$ Simon makes a similar error in failing to recognize that the proposals he makes for reducing undesirable advice will inevitably deter and reduce desirable advice as well. ${ }^{18}$

\section{A. The Root Problem of Incomplete Information}

Whatever criteria society uses to distinguish desirable from undesirable conduct, ${ }^{19}$ it faces the problem that any regime of legal sanctions will be imprecise because of incomplete information. Perfect sanctioning would require complete information supplied by reliable witnesses. ${ }^{20}$ But not all information can be observed. For example, even a reliable witness to the conduct in controversy usually cannot directly observe the actor's state of mind or internal physical condition. Even when physically possible, direct observation may involve prohibitive costs. Many acts must be observed, and reliable witnesses are expensive, in large part because a cumbersome system of secondary sanctions is often necessary to ensure their reliability. ${ }^{21}$

16. For a discussion of these and other articles, see infra section II.A.

17. For further discussion, see infra section II.A.

18. For further discussion, see infra section III.B.

19. Our analysis makes no assumption about what these criteria should be. In particular, we do not choose between the welfarist view that conduct is undesirable if and only if it causes harm exceeding the actor's gain, Shavell, supra note 4, at 128-29, and the view that at least some conduct is undesirable because it is intrinsically wrong rather than because it fails a utilitarian calculus. Cf. Alvin K. Klevorick, On the Economic Theory of Crime, in Nomos XXVII: CRIMINAL JUSTICE 289, 293-94 (J. Ruland Pennock \& John W. Chapman eds., 1985) (questioning whether an act's utility to a criminal offender should be taken into account in determining the social value of her conduct).

20. A reliable witness is physically and mentally competent, skilled in observation, knowledgeable about the subject matter being observed, and disinterested.

21. Massive videotaping of all human activity might avoid some of the problems raised by secondary sanctioning systems, but it would entail its own enormous financial costs. It would undoubtedly also require human monitors to process the resulting videotapes, which in turn requires some secondary sanctioning system to ensure the reliability of videotape monitors. Of course, it would involve other enormous costs in terms of desirable conduct deterred, invasion of privacy, and general spiritual impoverishment, as the text following this footnote indicates. The patent grotesqueness of the suggestion is itself evidence that a society may find that other goods provide ample compensation for the imprecision of its sanctioning system. 
But some of the most significant costs of collecting information are not financial. Surveillance is often intrinsically harmful insofar as it invades privacy or restricts personal liberty. Moreover, the observation needed to distinguish desirable from undesirable conduct can itself have the perverse effect of deterring desirable conduct. For example, observing the industrial design process may detect defective designs but discourage technical innovation (which might even improve safety) because of the risk that trade secrets would be disclosed. Close observation of family interaction may detect child abuse but destroy the intimacy and spontaneity that are among the principal goods of family life. At some point, concerns about these nonfinancial costs of surveillance justify placing limits, such as evidentiary privileges, on the ability of reliable witnesses to observe or report disputed conduct.

In short, obtaining reliable, complete information is not only unfeasible but undesirable. Hence, even in an ideal legal system, tribunals would have incomplete information and thus encounter difficulty determining with confidence whether a party has engaged in desirable or undesirable conduct. In a more realistic world, tribunals will (even if conscientious) also make errors in assessing the presented information or determining whether that information evidences undesirable conduct under the existing law.22 As a result, any legal regime will make two kinds of errors: (1) failing to detect and punish some undesirable conduct; and (2) mistakenly punishing some desirable conduct.

\section{B. The Three Basic Strategies for Optimizing Sanctions}

Legal regimes employ various strategies to address this unavoidable imprecision. All, however, share a common problem. In the absence of the information necessary to distinguish with certainty between desirable and undesirable conduct, the strategies can improve the sanctioning and deterrence of undesirable conduct only at the cost of sanctioning and deterring desirable conduct.

Before describing these strategies, it is worth addressing a basic objection to the analysis: namely that not all conduct can be described as desirable or undesirable. On many subjects, one might argue (and we would agree), the proper stance of the legal regime is agnosticism because individuals ought to have the autonomy to choose what they want to do. There is, however, no difficulty in incorporating this observation into the general framework of this article. Where society

22. Sometimes the law will itself be vague in defining undesirable conduct. This effectively gives tribunals lawmaking discretion to define undesirable conduct. Because they will sometimes exercise this discretion in ways that deviate from what society would wish, this is another source of legal error. 
values the freedom to do as one sees fit, any conduct individuals choose is socially desirable in the sense used here because it would be undesirable to deter individuals from choosing that conduct freely. The legal regime can overdeter conduct that furthers autonomy as well as conduct that furthers other social values.

\section{Probabilistic Standards of Proof}

One strategy for coping with uncertainty about what conduct is undesirable is to have tribunals determine on a case-by-case basis the probability that any given conduct was undesirable and then apply sanctions when that probability exceeds a certain threshold. The legal regime might, for example, define sanctionable conduct in terms of characteristics that strongly correlate with desirability but could only be reliably established with information that is impossible or too costly to obtain.

For example, consider a rule that conditions sanctions on a party's subjective good faith or intent. Under such a rule, adjudication of whether the sanctionable conduct occurred must rest either on partial information or on information of low reliability, such as the testimony of the interested parties. Such adjudication will inevitably be rough and uncertain, turning on the tribunal's extrapolation from existing facts, its assessment of the witnesses' general propensity to lie or forget, their incentives and opportunity to lie in the particular case, and so forth.

Tribunals might then accommodate the resulting uncertainty by demanding only proof that the probability that the sanctionable conduct occurred meets a certain threshold. But the lower the probability needed to punish undesirable conduct, the more that inaccurate adjudication will punish and deter desirable conduct. The higher the probability, the more undesirable conduct will go unpunished and underdeterred. An optimal probability will leave some desirable conduct punished and overdeterred and some undesirable conduct unpunished and underdeterred. ${ }^{23}$

If the underdeterrence of undesirable conduct becomes worrisome, the legal regime may lower the standard of proof to punish a greater

23. See Richard A. Posner, An Economic Approach to Legal Procedure and Judicial Administration, 2 J. Legal Stud. 399, 410-15 (1973); see also Thomas J. Miceli, Optimal Prosecution of Defendants Whose Guilt Is Uncertain, 6 J.L. ECON. \& ORG. 189, 196-97 (1990). The appropriate standard of proof, and the degree of over- and undersanctioning, will also depend on the levels of litigation efforts by prosecutors, see id. at 189-90, 195-96, 200-01, and defendants. See Daniel L. Rubinfeld \& David E.M. Sappington, Efficient Awards and Standards of Proof in Judicial Proceedings, 18 RAND J. ECON. 308 (1987). But adjustments in, or based on, litigation efforts cannot eliminate the over- and undersanctioning problem. 
percentage of undesirable acts. The regime might, for example, require proof of negligence instead of scienter to establish fraud in soliciting proxies. Or the regime might change the standard of proof indirectly (for example, by making a penalty civil instead of criminal) or de facto rather than de jure (for example, by appointing judges who are less sympathetic to defendants). All these types of adjustments have been tried.

But any adjustment has trade-offs. A lower standard of proof reduces underdeterrence but results in greater overdeterrence of desirable acts. Federal proxy regulation is illustrative: it now stands accused of reducing fraudulent proxy solicitations at the cost of discouraging any communication among shareholders at all. ${ }^{24} \mathrm{~A}$ higher standard of proof, on the other hand, would ameliorate this overdeterrence of desirable communications but would result in greater underdeterrence of undesirable fraud.

\section{Bright-Line Rules}

Alternatively, the regime can define sanctionable conduct using criteria that can be observed at a low cost and with a high degree of confidence. ${ }^{25}$ Instead of defining sanctionable conduct in terms of the party's state of mind or other difficult to observe information, the regime may define it in terms that expressly disclaim reliance on state of mind or allow proof based on easily observable features of the parties' conduct. Examples include the objective theory of contract, the statute of frauds, various per se rules of liability under section 1 of the Sherman Act, ${ }^{26}$ and the securities law prohibition on short-swing trading by statutory insiders whether or not they possess inside

24. See, e.g., Bernard S. Black, Shareholder Passivity Reexamined, 89 Mich. L. REv. 520, 539-40 (1990); John Pound, Proxy Voting and the SEC: Investor Protection Versus Market Efficiency, 29 J. FIN. ECON. 241, 242, 271 (1991).

25. See Issac Ehrlich \& Richard A. Posner, An Economic Analysis of Legal Rulemaking, $3 \mathrm{~J}$. Legal STUd. 257 (1974); Duncan Kennedy, Form and Substance in Private Law Adjudication, 89 HARV. L. REv. 1685, 1687-1701 (1976). For our purposes, the key difference between rules and standards is that the former rely on criteria that are easy to detect and apply whereas the latter rely on criteria that are harder to detect and apply but are more closely correlated to the desirability of the underlying conduct. Our definition thus parallels Ehrlich and Posner's but differs from that used by others, who distinguish rules from standards based on whether their content is set ex ante or ex post, see Louis Kaplow, Rules Versus Standards: An Economic Analysis, 42 Duke L.J. 557, 560 (1992), or whether they are simple or detailed. Id. at 560 n.4 (collecting sources). It seems to us that we often have ex ante standards (for example, the antitrust rule of reason) as well as rules, and that we could have ex post versions of either. Similarly, rules can be simple (speed limits) or complex (the tax code), and standards can be complex (15-factor balancing tests) or simple (intentional battery).

26. Act of July 2, 1890, ch. 647,26 Stat. 209 (codified as amended at 15 U.S.C. $\S \S 1-7$ (1988)). 
information. ${ }^{27}$

Detecting and punishing a violation of such bright-line rules will be easier. ${ }^{28}$ However, because such rules use criteria that correlate less well with the desirability of the underlying conduct, the defined scope of sanctionable conduct will be over- or underinclusive. ${ }^{29}$ Either some desirable conduct will be defined as sanctionable or some undesirable conduct will not. In all likelihood, both will be true.

As compared with the first strategy, such a bright-line strategy reduces uncertainty about the applicability of sanctions. ${ }^{30}$ This strategy will therefore deter parties less from engaging in conduct that lies outside the scope of the defined sanctionable conduct, but which might be mistaken for it. But, to the extent that nonsanctionable conduct under the bright-line rule encompasses undesirable as well as desirable conduct, it is not clear that this lessening of deterrence will always be socially beneficial. It may encourage "the proverbial 'bad man' to "walk the line" " and thus exploit the resulting loopholes. ${ }^{31}$

If the nonsanctionable conduct encompasses only desirable conduct, this lessened deterrence will, standing alone, be desirable. But obtaining this social benefit has a cost: the deterrence of desirable conduct within the scope of sanctionable conduct will increase. There are two reasons for this. First, punishment of desirable conduct within the bright-line rule will be more certain than if a standard applied. Second, if under the rule all nonsanctionable conduct is desirable, then the rule must by definition include all undesirable acts. Designing such a broad rule is almost sure to increase the rule's overinclusion of desirable conduct.

\section{Adjusting Penalties}

The limitations of these two basic approaches to identifying sanctionable conduct also infect strategies that involve adjusting the level

27. Securities Exchange Act of 1934, Pub. L. No. 73-291, §16(b), 48 Stat. 881 (codified as amended at 15 U.S.C. $\$ 78(a)-(l l)(1988))$.

28. Moreover, individuals generally have more incentive to learn about, and thus have their behavior influenced by, rules rather than standards for two reasons. First, individuals benefit more from learning about rules because they offer more precise predictions of adjudication than standards do. Second, to the extent rules are easier to learn, the cost of learning them will be lower. Cf. Kaplow, supra note 25, at 571-72 (using different definition of rules and standards). This second factor, however, may not always hold. Learning the standard of negligence, for example, seems easier and less costly than learning some provisions of the tax code.

29. See John E. Calfee \& Richard Craswell, Some Effects of Uncertainty on Compliance with Legal Standards, 70 VA. L. REV. 965, 1000 (1984); Ehrlich \& Posner, supra note 25, at 268; Kennedy, supra note 25, at 1689-90; see also United States v. United States Gypsum Co., 438 U.S. 422, 442 n.17 (1978) (recognizing that per se rules increase deterrence of desirable conduct).

30. See Ehrlich \& Posner, supra note 25, at 261-64; Kennedy, supra note 25, at 1688-89.

31. Kennedy, supra note 25 , at 1696. 
of actual penalties imposed. For example, a classic strategy for addressing the underdeterrence that results from imperfect information is to increase the penalties imposed on those determined to engage in undesirable conduct to reflect the probability that they might have escaped detection and punishment. ${ }^{32}$ If, for example, only one-third of antitrust violations are detected and punished, then trebling damages will produce the same expected sanction as single damages and one hundred percent detection and punishment. Assuming the actual penalties imposed can be set high enough, then, despite infrequent punishment, expected sanctions can outweigh the benefits of (and thus deter) undesirable conduct.

An initial problem with this strategy is that the legal regime cannot always set penalties high enough to eliminate underdeterrence. If the frequency of detection and punishment is low, it may be impossible to raise sanctions sufficiently to deter all undesirable conduct. Or the level of sanctions required to eliminate underdeterrence may be disproportionate, unfair, cruel, beyond individual actors' wealth (so that increasing sanctions yields no additional deterrent benefit), or, in the case of extensive incarceration, too costly to administer. ${ }^{33}$

A more general problem is that adjusting penalties can eliminate underdeterrence only at the cost of increasing overdeterrence. ${ }^{34}$ If, given incomplete information, either the definition of sanctionable conduct or the uncertainties of its adjudication often subject desirable conduct to a risk of sanctions, then an increase in penalties to increase deterrence of undesirable conduct will increase deterrence of desirable conduct as well. ${ }^{35}$ If, to avoid this result, the legal regime defines or

32. See, e.g., JeREMy Bentham, The Theory of Legislation 325-26 (C.K. Ogden ed. \& Richard Hildreth trans., Harcourt Brace \& Co. 1931) (1789); A. Mitchell PolinsKY, AN InTRODUCTION to LAw AND Economics 75-86 (2d ed. 1989); Gary S. Becker, Crime and Punishment: An Economic Approach, 76 J. Pol. Econ. 169, 183-85 (1968); Jeffrey S. Parker, The Economics of Mens Rea, 79 VA. L. REV. 741, 748-54 (1993) (collecting sources).

33. See Stephen McG. Bundy \& Einer R. Elhauge, Do Lawyers Improve the Adversary System? A General Theory of Litigation Advice and Its Regulation, 79 CAL. L. REV. 313, 390-91 (1991); Reinier K. Kraakman, Gatekeepers: The Anatomy of a Third-Party Enforcement Strategy, 2 J.L. ECON. \& ORG. 53, 56-57 (1986).

34. When economists describe "overdeterrence," they generally focus on the consumption of social resources in preventing an offense, see Parker, supra note 32, at $757 \mathrm{n} .46$, such as the expenditure of money on enforcement and punishment efforts. See id. at 750-53. Our focus, however, will be on the deterrence of desirable behavior caused as an incident of efforts to deter undesirable behavior.

35. See Calfee \& Craswell, supra note 29 , at 995-97. Risk aversion will heighten the increased overdeterrence because high sanctions with a low probability of application impose greater risk-bearing costs than low sanctions with a higher probability. See A. Mitchell Polinsky \& Steven Shavell, The Optimal Tradeoff Between the Probability and Magnitude of Fines, 69 AM. ECON. REv. 880 (1979). Of course, to the extent undesirable actors are also risk averse, risk aversion will tend to reduce underdeterrence as well, but one might expect risk-bearing costs to be more significant for desirable actors because their probability of punishment will be lower. 
adjudicates sanctionable conduct in a way that eliminates the punishment and deterrence of desirable conduct, then some undesirable conduct will also remain effectively unpunished and undeterred no matter how much penalties are increased.

\section{Individual Variation}

The three recognized strategies also face problems of over- and undersanctioning that result from individual variation. Actors differ in the benefits that they receive from the same conduct. In part, this depends on whether they share any societal belief that a given act is desirable or undesirable. It may also reflect the degree to which they fear extralegal sanctions, such as divine punishment, the reproach of conscience, or damage to their reputation, relationships, or future economic opportunities. ${ }^{36}$ Actors also differ in their aversion to risk, their perceptions of expected sanctions, and their ability and willingness to engage in rational calculation.

Such individual variation implies that a uniform schedule of expected sanctions will have different effects on different actors. Tribunals may attempt to adjust the actual sanctions imposed to compensate for this variation. However, such ad hoc, individualized efforts are likely to suffer from considerable imprecision because the preferences, beliefs, and character traits involved are difficult to identify with confidence. ${ }^{37}$ Where individualized sanction adjustments are infeasible, the optimal expected sanctions will depend on the mix of characteristics in the regulated population. Optimal sanctions will have to minimize under- and oversanctioning given the population's mix of characteristics and will thus underdeter undesirable acts or overdeter desirable acts by persons who are unusual in any of the above respects.

Actors vary not only in their response to legal regulation generally, but also in their response to the choice of particular sanctioning strategies. Like most rational actor accounts of legal advice, our baseline account assumes that actors are sanction optimizers. In deciding whether to engage in regulated conduct, the sanction optimizer is a Holmesian "bad man"38 who considers only the actual level of ex-

36. See, e.g., Parker, supra note 32, at $755 \&$ n.38 (collecting sources).

37. See generally Bundy \& Elhauge, supra note 33, at 390 (discussing problems of adjusting sanctions given individual variation); Kaplow \& Shavell, Legal Advice About Information, supra note 4 , at 591-93.

38. Oliver Wendell Holmes, JR., The Path of the Law, in Collected legal Papers 167,171 (1921) (introducing the "bad man"). 
pected legal sanctions and gives no independent weight to the fact that the conduct is legally prohibited or required.

Other actors, however, may respond more to the sanctionability of conduct than to the level of expected sanctions. Such actors, whom we characterize as "law abiding," tend to comply with what they understand to be their legal obligations regardless of the level of expected sanctions for failing to do so. ${ }^{39}$ For example, if the law forbids certain conduct outright, as does much of the criminal law, the law abider will not engage in it no matter how low the expected sanction. If the law permits conduct conditional on compensation for harm caused, as in much of tort and contract law, the law abider will wish to pay the full harm caused, whether or not he expects victims to sue or, if suit is brought, to prevail.

A population of actors that is generally law abiding may infiuence the mix of sanctioning strategies used by allowing the designers of the regime to focus on the definition of sanctionability rather than on the level of expected sanctions. Such a population, however, does not necessarily eliminate problems of over- and underdeterrence because, to the extent that law abiders respond simply to the fact that conduct is sanctionable, they will comply whether or not the definition of sanctionable conduct comports with social desirability. ${ }^{40}$

\section{Compensatory Subsidies: A Fourth Basic Strategy?}

In addition to the three recognized strategies, I.P.L. Png has suggested an ingenious fourth strategy for coping with legal error: coupling an adjustment in penalties with a general subsidy for all actors. ${ }^{41}$ Under this strategy, the legal regime would first increase penalties to

39. Law abidingness is independent of the content of the particular law and its congruence with the actor's own views of morality. Rather it represents the actor's tendency to comply with the law simply because it is the law. We need not take a position here on whether this tendency is most appropriately viewed as a preference or as an expression of a kind of practical reason different from economic maximization. See Lewis Kornhauser, Are There Cracks in the Foundations of Spontaneous Order?, 67 N.Y.U. L. REv. 647, 670-72 (1992) (reviewing ROBERT C. Ellickson, Order Without LaW: How Neighbors SeTtle Disputes (1991)).

40. If all actors were uniformly perfectly law abiding, then the regime could define conduct as sanctionable strictly in accord with its social desirability. Disputes would still arise about whether particular conduct was sanctionable because of good faith disagreements about the facts and the scope of sanctionability, and some of those disputes would be resolved erroneously. But imperfections in detection and adjudication resulting from the definition of sanctionability would not lead to over- or underdeterrence because they would not figure in compliance decisions even if known. Indeed, adjudication would have no deterrence function at all.

But of course not all actors are perfect law abiders. As long as a substantial set of actors respond to expected sanctions rather than sanctionability, the regime that wishes to optimize behavior is likely to adopt a definition of sanctionability that does not correspond precisely to social desirability for all the reasons stated above.

41. See generally I.P.L. Png, Optimal Subsidies and Damages in the Presence of Judicial Error, 6 INTL. REV. L. \& ECON. 101 (1986). We are indebted to Dan Rubinfeld for pointing out 
offset underdeterrence until the difference between the expected penalties for undesirable and desirable conduct equals the harm from acting undesirably. Then the legal regime would compensate for the expected penalties imposed on those acting desirably by giving all actors (desirable and undesirable alike) a subsidy sufficient to offset this overdeterrence effect. Png's strategy thus offers the promise of eliminating both the overdeterrence of desirable conduct and the underdeterrence of undesirable conduct despite the legal regime's imperfect ability to distinguish them.

An example might help. Suppose we wish to deter negligent driving but not non-negligent driving. Suppose further that all accidents give rise to claims and that, for a given accident, we can determine with eighty percent accuracy whether or not the driver was negligent. The actual penalty imposed on those judged to be negligent is $\$ 5000$. The expected penalty needed to deter all negligent driving is also $\$ 5000$. Under this regime, the expected penalty for driving negligently is $\$ 4000$ because twenty percent of those who drive negligently escape punishment. The expected penalty for driving non-negligently is $\$ 1000$ because twenty percent of non-negligent drivers are mistakenly found liable. Non-negligent driving would thus be overdeterred while negligent driving would remain underdeterred. To compensate for the underdeterrence, we might increase the penalty to $\$ 6250$. That would produce an expected penalty for negligent driving of $\$ 5000$, sufficient to eliminate underdeterrence. But the expected penalty for non-negligent driving would also increase, from $\$ 1000$ to $\$ 1250$, thus exacerbating overdeterrence. We seem to face a familiar trade-off.

Png's proposed solution to this dilemma has two elements. First, he would increase the actual penalty even further until the difference between the expected penalties for negligent and non-negligent driving equals $\$ 5000$. Here the necessary penalty would be $\$ 8333.33$. That would make the expected penalty for negligent driving equal to $\$ 6666.66$ and the expected penalty for non-negligent driving $\$ 1666.66$. Second, Png would give all drivers a subsidy of $\$ 1666.66$ for driving. The result is that the negligent driver would face an expected cost of $\$ 5000$ - the $\$ 6,666.66$ expected penalty minus the $\$ 1666.66$ subsidy - which is enough to deter all negligent driving. The non-negligent driver would face an expected cost of zero dollars, because the subsidy offsets the expected penalty. Overdeterrence is thus also seemingly eliminated, at least if one puts aside risk aversion.

that we have to address Png's strategy to establish our claim that the tradeoff between over- and underdeterrence is inevitable. 
Professor Png's strategy is undeniably ingenious. Moreover, it seems largely unappreciated in the legal literature. For several reasons, however, we do not believe that Png's strategy undermines our general conclusion that no legal regime can ever avoid the trade-off between over- and underdeterrence. ${ }^{42}$

To begin with, Png's reasoning depends on an isolated analysis of a single activity: driving. If the legal regime actually tried to pursue his strategy across the board to curb all forms of undesirable conduct without deterring desirable conduct, it would end up subsidizing all activities. Subsidies would be required not just for driving, but for skiing, flying, bus riding, or any other activity that might be penalized if performed undesirably. The subsidization used to encourage these socially optimal levels of driving will thus be undermined by the subsidization used to encourage socially optimal alternatives. What matters is not the absolute subsidy given to drivers but the relative subsidy between alternative activities. Png's strategy does not explain how subsidies can produce perfectly efficient choices between desirable and undesirable versions of a given activity without skewing choices among different desirable activities.

A related problem is that Png's analysis assumes parties should internalize only the physical harm caused by their activities. ${ }^{43}$ But activities would also impose another cost under a legal regime that employed his strategy: namely the cost of the subsidies that society must supply to offset the difficulty of distinguishing between desirable and undesirable versions of that activity. Let us call these costs imprecision costs. Because the level of difficulty involved in distinguishing between desirable and undesirable acts differs for different types of activities, some activities will produce higher levels of imprecision costs than others. Under Png's strategy, however, no activity would be forced to internalize its imprecision costs. It is not clear why this should be desirable. One might instead think that providing the incentives to encourage socially efficient choices between different activities would require forcing every activity to include all the costs - including the imprecision costs - entailed by that activity. Implicitly, that is precisely what a sanctioning regime without subsidies does.

Further, Png's analysis seems to assume that the collection and distribution of taxes and subsidies is costless. Taxes, however, pro-

42. It should be noted that Png himself makes no such grandiose claims for his strategy: our concern here is with the implications that might be drawn from his strategy.

43. Png, supra note 41, at 103 . Png also assumes that the private benefit from any activity equals the social benefit. If the private benefits are greater or less than the social benefits, his conclusions may not follow. 
duce their own inefficient effects on behavior: for example, they deter persons from engaging in those activities subject to taxation. There are also substantial direct costs to enforcing taxes, and high costs would have to be incurred to determine the size of subsidies, and who should receive them, under Png's approach. It is far from clear that the social inefficiencies produced by these taxes and subsidies would not outweigh any increased efficiency in behavior. ${ }^{44}$

Finally, individual variation poses insurmountable problems for Png's approach. To implement his approach, the legal regime must calculate subsidies. This requires knowing how often each individual engages in a particular activity, the probability he would have to pay damages if he engages in a desirable version of that activity, and the harm he would produce. ${ }^{45}$ Because individuals differ on all these matters, any uniform schedule of subsidies will produce substantial overand undersanctioning. If the regime instead calculates different subsidies for each individual, it will need a secondary system of adjudication to determine how much of a subsidy each individual should receive. This secondary system of adjudication would have to contend with the same problems of imperfect information that plague the primary system of adjudication.

\section{Conclusion}

Given imperfect information, the best society can do is to design a sanctioning regime that achieves the trade-off between undersanctioning undesirable conduct and oversanctioning desirable conduct that seems the most optimal. The optimal compromise will most likely entail a combination of strategies: adjudicating or defining sanctionable conduct in a way that renders some desirable conduct sanctionable while reducing actual sanctions below the level that would be optimal if all sanctionable conduct were undesirable. This solution will have some adverse effects: optimal expected sanctions will still be high enough to deter some desirable acts, but not high enough to deter all

44. Cf. Richard A. Posner, Taxation by Regulation, 2 BELL. J. ECON. \& MGMT. SCI. 22, 4145,47 (1971) (observing that there is no a priori reason to believe the inefficiencies caused by redistributive taxation are lower than the inefficiencies caused by redistributive regulation). If the government (rather than private litigants) collects the extra penalties used under the Png strategy, this added revenue may help offset the cost of the subsidies.

45. See Png, supra note 41, at 103. For the particular activity Png analyzed, driving, a convenient way of tying the subsidy amount to the activity level would be to subsidize gasoline. Alternatively, this might be an argument for not raising the gasoline tax as high as would otherwise be necessary to offset driving externalities like pollution. But this strategy would not measure other activity risk factors, such as when and where the driving occurred, and collecting that sort of data might violate privacy or itself deter desirable activity. See supra section I.A. In any event, most human activities lack any similar convenient way of metering activity levels. 
undesirable conduct. ${ }^{46}$ Given the unavoidable trade-off, however, the success of any sanctioning regime cannot fairly be judged by whether it wholly eliminates over- or undersanctioning. Rather, it must be judged by whether it minimizes the total adverse consequences of undersanctioning undesirable conduct and oversanctioning desirable conduct.

Although this article stresses behavioral measures, such as overand underdeterrence, our conclusion does not depend on the measure used to evaluate the consequences of under- or oversanctioning. In particular, our conclusion is consistent with the view that punishing innocent defendants, failing to exact retribution from wrongdoers, or inadequately compensating deserving plaintiffs is wrong because it is inherently unjust rather than because of its behavioral consequences. Under such nonbehavioralist views, the sanctioning regime would simply aim to minimize the total injustice resulting from over- and undersanctioning. The key is not the measure of value but the recognition that, under any measure, sanctioning undesirable conduct must be traded off against sanctioning desirable conduct.

\section{The Desirability of Advice About Sanctions AND the CATEgORICAL APPROACH}

As we describe in more detail below, the desirability of legal advice is sometimes viewed as depending on the category of function it performs. One important view distinguishes between advice that simply informs persons of the scope and level of expected sanctions and advice that assists parties in altering expected sanctions. The most desirable category of advice is usually considered to be advice that merely informs clients about whether certain conduct is illegal. Advice that also informs clients about the magnitude of legal penalties and the probability they will be imposed is viewed with more suspicion because legal penalties or enforcement may be insufficient. But the general attitude toward such advice is still favorable, on the assumption that the object of reform should not be the advice but rather the laws that provide insufficient penalties and enforcement. With more appro-

46. Steven Shavell demonstrates that setting the level of sanctions for nonproduction of evidence in this manner may be optimal when the tribunal cannot be sure whether a party is failing to produce evidence. See Steven Shavell, Optimal Sanctions and the Incentive To Provide Evidence to Legal Tribunals, 9 INTL. REV. L. \& ECON. 3, 4-5 (1989). But the point is clearly more general. Whenever tribunals cannot distinguish with certainty between desirable and undesirable conduct, then - whether the conduct occurs inside or outside litigation - the sanctioning regime can minimize the total disvalue of undersanctioning undesirable conduct and oversanctioning desirable conduct by adjusting not only the level of sanctions, but also, through adjudication or definition, the scope of conduct subject to sanctions. 
priate expected penalties, it is felt, such advice would desirably lead persons to comply with the law.

Under this initial categorical approach, both of the above forms of advice - which simply communicate the existing scope and level of expected legal penalties - are viewed more favorably than advice that gives persons knowledge about how to alter expected legal penalties. This latter type of advice, it is felt, helps persons evade their legal responsibilities. It does so either by altering the information created about contemplated conduct or by altering (typically in litigation) the information revealed about past conduct.

A version of the categorical distinction between advice that informs persons about expected sanctions and advice that alters those sanctions appears to underlie what William Simon has described as the regulatory approach to legal ethics. ${ }^{47}$ Under the regulatory approach, lawyers should distill and transmit information but should not manipulate that information to further their clients' goals. Recently, an economic basis for such an approach - along with a more precise outline of its contours - has been spelled out by Kaplow and Shavell in a series of articles.

The point is of more than academic interest. Such a categorical distinction may underlie a current rule of professional ethics. Most significantly, Model Rule of Professional Conduct Rule 1.2(d) states:

A lawyer shall not counsel a client to engage, or assist a client, in conduct that the lawyer knows is criminal or fraudulent, but a lawyer may discuss the legal consequences of any proposed course of conduct with a client and may counsel or assist a client to make a good faith effort to determine the validity, scope, meaning or application of the law. ${ }^{48}$

The comment to the rule explains:

There is a critical distinction between presenting an analysis of legal aspects of questionable conduct and recommending the means by which a crime or fraud might be committed with impunity. ... [T] he lawyer is required to avoid furthering the [wrongful] purpose, for example, by suggesting how it might be concealed. ${ }^{49}$

On its face, Rule 1.2 thus seems to make a categorical distinction between advice that merely informs a client about expected sanctions and advice that lowers those expected sanctions. ${ }^{50}$ There are thus live

47. Simon, supra note 1 , at 1085-87.

48. Model Rules of Professional Conduct Rule 1.2(d) (1992).

49. Model Rules of Professional Conduct Rule $1.2 \mathrm{cmt}$. (1992).

50. Unlike the Model Rules, the Model Code of Professional Responsibility does not (at least not expressly) draw such a distinction in its crime-fraud exception. See MODEL Code of ProFESSIONAL RESPONSIBILITY DR 7-102(A)(7) (1980) ("[A] lawyer shall not ... [c]ounsel or assist his client in conduct that the lawyer knows to be illegal or fraudulent."). But the relevant Ethical Considerations under the Code appear to do so. MODEl CODE OF PROFEssional. ResponsI- 
legal issues about whether such a distinction should be recognized within the crime-fraud exception and potential legal issues about whether the law should extend such a distinction beyond the crimefraud area.

In practice, the posited distinction may break down. If a lawyer can tell the party the legal consequences (including the magnitude and probability of sanctions) that attend each of a number of possible courses of conduct that have the same undesirable purpose, the client will have no difficulty choosing the one that results in the lowest expected sanction. ${ }^{51}$ But our focus here is less on practical objections to possible proposals than on the basic question whether the distinction, if definable, is justifiable.

Another implication of a categorical approach that disfavors advice that assists a party in altering expected sanctions is that litigation advice is particularly suspect; this, of course, is Kaplow and Shavell's conclusion. An alternate categorical approach to advice, recently characterized by David Wilkins as "the single most important contextual distinction in legal ethics,"52 however, takes a precisely opposite tack, viewing litigation advice as categorically more desirable than primary conduct advice. In litigation, this approach argues, advice is reflected primarily in conduct taking place before the tribunal, where both parties have legal advice. In contrast, advice about primary conduct takes place in private and frequently only the actor has legal advice. The private and unilateral quality of conduct advice makes it unusually dangerous and justifies subjecting it to greater restrictions.

This claimed categorical distinction also underlies an important current debate in professional ethics, a debate that was highlighted in the Kaye, Scholer case. Kaye, Scholer represented Lincoln Savings in connection with an audit by the Federal Home Loan Bank Board. Following its seizure of Lincoln, the Office of Thrift Supervision, the Board's successor, brought a widely publicized enforcement proceeding against Kaye, Scholer, charging that it had violated its obligations to both Lincoln and the Board, that those violations had contributed to delays in closing Lincoln, and that Kaye, Scholer was liable for

BILITY EC 7-5 (1980) ("A lawyer should never. . counsel his client on how to violate the law and avoid punishment therefor."); see also MODEL CODE of Professional Responsibility EC 7-5 n.14 (1980) (quoting ABA Comm. on Professional Ethics, Formal Op. 281 (1952): "There is a sharp distinction, of course, between advising what can lawfully be done and advising how unlawful acts can be done in a way to avoid conviction."). See generally CHARLES W. WOLFRAM, MODERN LEGAL ETHICS § 13.3.2 (1986).

51. For a description of how some lawyers accomplish this result, see KENNETH MANN, Defending White-Collar Crime: A Portrait of Attorneys at Work 109-11, 115-20 (1985) (describing compliance advice with respect to government subpoenas).

52. Wilkins, supra note 8 , at 1155 . 
losses resulting from those delays. While some of the government's claims may well have been consistent with traditional ethical prohibitions on knowingly assisting in client crime or fraud, others could be read as imposing more demanding obligations. ${ }^{53}$

Kaye, Scholer ultimately settled the claims against it for $\$ 41$ million. What is of interest is that the central element of the firm's defense to the charge was that, "with respect to virtually all of the matters at issue, [Kaye, Scholer] was retained as litigation counsel by Lincoln."54 Relying on an opinion from distinguished ethics expert Geoffrey Hazard, Kaye, Scholer argued that, given the categorical status of its legal work, it would be both unprecedented and unwise to impose upon it any of the more demanding standards of conduct implied in the OTS Notice of Charges.55 Subsequent observers of the case, while they have criticized Kaye, Scholer's reliance on the distinction between advice about litigation and advice about primary conduct given the facts of the case, largely appear to accept the distinction. ${ }^{56}$

We begin our investigation of these conflicting categorical approaches by describing in section II.A the Kaplow and Shavell models and by taking a critical look at the assumptions needed to reach their conclusions. We then demonstrate in section II.B that, with more realistic assumptions, one reaches very different - and often precisely opposite - conclusions about categories of legal counseling. Finally, in section II.C we turn to categorical distinctions between the social desirability of advice in litigation and advice about primary conduct. We reject both Kaplow and Shavell's claim that litigation advice is categorically inferior to advice about primary conduct and the claim by Fuller, Wilkins, and Hazard that the reverse is true.

\section{A. The Kaplow and Shavell Models}

In their seminal work in the area, ${ }^{57}$ Kaplow and Shavell use economic models of legal advice to reach five basic conclusions about legal advice. First, "when advice is sought regarding whether acts are

53. For discussion, see Howell E. Jackson, Reflections on Kaye, Scholer: Enlisting Lawyers To Improve the Regulation of Financial Institutions, 66 U.S.C. L. REv. 1019, 1025-32 (1993) (outlining tensions between traditional view of lawyers' ethics and OTS's view); Wilkins, supra note 8, at 1157-59 (discussing some OTS claims arguably in tension with traditional view).

54. Memorandum, supra note 13.

55. See Summary of the Expert Opinion of Geoffrey C. Hazard, Jr., reprinted in THE ATTORNey Client Relationship After Kaye, Scholer 381, 396 (PLI Corp. Law \& Practice Course Handbook Series No. 779, 1992) [hereinafter THE ATTORNEY ClIENT RELATIONSHIP].

56. Wilkins, supra note 8, at 1183 ("[A]s a general matter, Kaye Scholer's position scems uncontroversial."). 4.

57. See Kaplow \& Shavell, Legal Advice About Information, supra note 4; Shavell, supra note 
sanctionable, and the advice is definitive, then advice can lead only to desirable changes in behavior." 58 This conclusion is based on the observation that, to the extent that it alters behavior, advice about sanctionability will have one of two consequences. Either it will lead parties to commit unsanctionable acts that, without advice, they would have thought sanctionable, or it will lead them to avoid sanctionable acts that, without advice, they would have thought unsanctionable. ${ }^{59}$ Either of those behavioral changes is assumed to be socially desirable. 60

Kaplow and Shavell's second and third conclusions concern legal counseling that informs clients about the level of expected legal sanctions. The second conclusion is that "the provision of legal advice about the probability and magnitude of sanctions will lead to socially desirable changes in behavior if the probability and magnitude of sanctions are set so that expected sanctions equal the harm that results from acts."61 The third conclusion is that "the desirability of the effect of advice about contemplated acts is ambiguous when the legal system's sanctions do not properly reflect harm caused." 62 Both these conclusions are framed in terms of whether expected sanctions equal the "harm" caused by the conduct because Shavell's initial model adopted the utilitarian assumption that an act is socially undesirable if and only if the harm done exceeds the party's gain. ${ }^{63}$ But Shavell stresses that he uses this utilitarian assumption merely to allow him to describe an undesirable category of acts, and that his analysis applies equally if one uses other criteria for defining undesirable conduct. ${ }^{64}$ In their subsequent work, Kaplow and Shavell generalize this conclusion to assert that advice about the level of expected legal sanctions will tend to be socially beneficial if that level is set "appropriately."65

These generally favorable conclusions about advice that informs clients about the scope or level of expected sanctions contrast with Kaplow and Shavell's negative conclusions about advice that alters those sanctions. Their fourth conclusion is that, "when advice helps to lower (rather than only to inform about) the probability or magni-

58. Shavell, supra note 4, at 138 (emphasis added); see also id. at 129.

59. Id. at 129.

60. Id.

61. Id. at 135; see also id. at 138; Kaplow \& Shavell, Legal Advice About Information, supra note 4 , at 597 .

62. Kaplow \& Shavell, Legal Advice About Information, supra note 4, at $597 \mathrm{n.77}$; see also Shavell, supra note 4 , at 138-39.

63. Shavell, supra note 4 , at 128-29.

64. Id. at 129 n.16.

65. Kaplow \& Shavell, Legal Advice About Information, supra note 4, at 597. 
tude of sanctions, advice can lead only to the commission of undesirable acts and is therefore undesirable."66 (Their models do not consider advice that helps raise the level of expected sanctions for other parties.)

Advice in litigation, which helps alter sanctions for past conduct, is also viewed as dubious. Kaplow and Shavell observe that evidentiary sanctions are often insufficient to force the revelation of all information in a client's possession. ${ }^{67}$ They then assume, on the premise that this assumption alters the extent but not the nature of their conclusions, that lawyers exercise perfect control over the client's information. ${ }^{68}$ Thus, in their model, litigation advice has only the effect of improving the client's selection of information to present to the tribunal from this controlled set of information. Litigation advice should accordingly increase the favorable information presented to the tribunal and decrease the unfavorable information presented. ${ }^{69}$ Kaplow and Shavell therefore conclude that litigation advice lowers the expected sanctions of those who receive it and has an ambiguous effect on the accuracy of adjudication and the behavior of individuals. ${ }^{70}$ Hence their fifth conclusion is that litigation advice, or more generally advice about how to challenge or defend past primary conduct, has "questionable social value."71

This chain of reasoning leads to their overall conclusion that there exists a sharp contrast between litigation advice and legal counseling provided before contemplated primary conduct:

There is a general reason to believe that legal advice provided when individuals are deciding how to act will tend to be socially beneficial. Such advice informs individuals before they act about the sanctions the legal system actually employs. As a result, individuals will be led to behave desirably if the level of sanctions is set appropriately. . . .

The socially desirable character of legal advice offered ex ante stands in sharp contrast to the questionable social value of advice offered during

66. Shavell, supra note 4, at 139 (emphasis added); see also id. at 137 ("The provision of legal advice that lowers the probability or magnitude of sanctions is socially undesirable because it can lead only to an increased number of socially undesirable acts.").

67. Kaplow \& Shavell, Legal Advice About Information, supra note 4, at 571-75. The reasonableness of this assumption is, of course, confirmed by scholarly and nonscholarly studies of the litigation process. See, e.g., Frank, supra note 1, at 85-86 (witnesses frequently lie and get away with it); Wayne D. Brazil, Views from the Front Lines: Observations by Chicago Lawyers About the System of Civil Discovery, 1980 AM. B. FounD. RES. J. 219, 225 (many civil cases conclude with relevant and material information not disclosed).

68. Kaplow \& Shavell, Legal Advice About Information, supra note 4, at 576.

69. Id. at $568,577,581,595$.

70. Id. at 568-69, 581, 586, 596, 603, 614 .

71. Id. at 597, 614; see also Kaplow \& Shavell, Legal Advice About Acts Already Committed, supra note 4 , at 149 . 
litigation. ${ }^{72}$

We will return to the litigation advice side of this asserted sharp contrast in section II.C. For now, let us reexamine the premises underlying the conclusion that advice that merely informs clients about the scope and level of expected sanctions is, if those sanctions are "set appropriately," desirable.

The first conclusion regarding advice about the scope of sanctions (that is, advice about sanctionability) rests on the premises that causing parties to commit unsanctionable acts, or to avoid sanctionable acts, is by definition desirable. ${ }^{73}$ With the benefit of the analysis in Part $\mathrm{I}$, it is evident that this first premise is equivalent to assuming that the law is never underinclusive: any conduct outside the realm of sanctionability is assumed desirable. Kaplow and Shavell's second premise is equivalent to assuming the law is never overinclusive or overdeterring: any conduct that would be deterred by knowledge of its sanctionability is assumed undesirable. Neither of these assumptions seems very plausible.

The premise underlying the conclusions regarding advice about the level of expected sanctions (that is, advice about the probability and magnitude of sanctions) is that the "appropriate" level of expected sanctions equals the harm the conduct causes. We do not wish here to quarrel with the utilitarian assumption that the sole measure of social desirability is whether the private benefit exceeds the harm to others; after all, Kaplow and Shavell state that they adopt this assumption solely to define a class of undesirable conduct. ${ }^{74}$ Rather the key point for present purposes is that, under this definition of undesirability, Kaplow and Shavell's notion of the "appropriate" level of expected sanctions is perfect in the sense that it will deter every undesirable act and no desirable acts. ${ }^{75}$ Because an undesirable act is (by definition) one that causes more harm to others than gain to the actor, expected sanctions equal to that harm will always deter it. Because a desirable act is (by definition) one that causes more gain to the actor than harm

72. Kaplow \& Shavell, Legal Advice About Information, supra note 4, at 597 (footnote omitted); see also id. at 614:

Skepticism about the value of legal advice in litigation is suggested by the manner in which it differs from advice provided before people act. The latter type of advice will lead individuals to behave more in accord with the law. Advice provided in litigation, after individuals have acted, has no similar general tendency.

73. See supra text accompanying notes 58-60.

74. See supra text accompanying note 64 .

75. The same can be said for Kaplow and Shavell's definition of the appropriate level of strict liability sanctions in Louis Kaplow \& Steven Shavell, Private Versus Socially Optimal Provision of Ex Ante Legal Advice, 8 J.L. ECON. \& ORG. 306 (1992), which leads them to the conclusion that advice about appropriate strict liability sanctions always improves behavior. See id. at 309 . 
to others, expected sanctions equal to that harm will never deter it. Under a view that defines undesirable conduct differently, this is equivalent to assuming that the regime of "appropriate" sanctions can perfectly distinguish between desirable and undesirable conduct.

It is thus not surprising that, under this assumption, advice that informs parties about the level of appropriately set expected sanctions is always desirable. Because such sanctions perfectly deter undesirable conduct without deterring desirable conduct, no ill can follow from disseminating information about such sanctions. Any ill effects that actually flowed from advice would thus seem to be the fault of the law that "inappropriately" set the level of expected sanctions. Nor is it surprising that advice that alters the appropriate level of expected sanctions would receive unfavorable reviews. Tampering with perfection can never constitute an improvement.

But, given our analysis in Part I, the implicit assumption of perfection is unrealistic. Because even optimal sanctions cannot perfectly distinguish between desirable and undesirable conduct, it makes no sense to judge advice using a measure of appropriate sanctions that can never be achieved. And the analysis of advice under such an optimal but imperfect regime leads, as we will see in the next section, to quite different conclusions about the desirability of such advice.

\section{B. The Effects of Advice About Optimal but Imperfect Sanctions}

Legal advice about the sanctions applicable to contemplated conduct can affect behavior in one of two ways. First, it can correct misperceptions actors may have about expected sanctions. Second, it can help actors affect the level of expected sanctions. Because of the various inevitable imperfections in any sanctioning regime, either form of advice about legal sanctions will have many adverse effects, even when sanctions are optimal. Our analysis suggests, however, that their social desirability is not, overall, that different. Moreover, we conclude that, despite these adverse effects, the overall behavioral consequences of either form of advice will (absent a skewed distribution of legal ignorance) tend to be socially desirable if society has set sanctions to optimize behavior.

\section{Advice that Corrects Misperceptions About Expected Sanctions}

Legal advice can correct misperceptions about expected sanctions in a variety of ways. It can inform actors that they have over- or underestimated the magnitude of sanctions. They might, for example, learn that, if a certain tax deduction they are thinking of taking is disallowed, the penalties are higher or lower than they thought. Ad- 
vice might also inform actors that they have over- or underestimated the probability that sanctions will be imposed. They might, for example, learn that the odds of being audited are lower or higher than they believed. Finally, advice might inform actors that they have over- or underestimated the scope of conduct subject to sanctions. The deductions they can legally take might, for example, be broader or narrower than they thought.

If the sanctioning regime could distinguish perfectly between desirable and undesirable conduct (and thus never sanctioned or deterred desirable conduct) and if it could also adjust expected sanctions perfectly (so that expected sanctions always exceeded the gain derived from undesirable acts), then advice that corrected misperceptions about expected sanctions would always be socially desirable because it would never discourage desirable acts or encourage undesirable acts. But, as we established in Part $\mathrm{I}$, such a perfect sanctioning regime is both implausible and undesirable. Thus even a sanctioning regime that optimizes behavior will underdeter some undesirable conduct and overdeter some desirable conduct. Moreover, such an optimal regime is likely to manifest not only over- and underdeterrence in the level of expected sanctions, but also over- and underinclusion in the scope of conduct subject to sanctions.

Correcting misperceptions of either the scope or level of expected sanctions will thus have mixed behavioral consequences. It increases the likelihood that actors will engage in any conduct - desirable or undesirable - when they learn that expected sanctions for that conduct are lower than they thought. It reduces the likelihood of that conduct when actors learn that expected sanctions are higher than they thought. ${ }^{76}$ Some of the errors unadvised actors might make are socially undesirable: they might overestimate expected sanctions for desirable conduct or underestimate expected sanctions for undesirable conduct. Correcting these errors will have desirable effects because it increases the likelihood that actors will commit desirable acts or forgo undesirable acts. Other errors are socially desirable: unadvised parties might overestimate expected sanctions for undesirable conduct or underestimate expected sanctions for desirable conduct. ${ }^{77}$ Correcting these errors will have undesirable effects because it increases the likelihood that actors will commit undesirable acts or forgo desirable acts.

76. Parties with advice may also change their desirable or undesirable behavior because they are risk averse and discover that, although expected sanctions are at the level they expected, they have incorrectly estimated the magnitude of the sanction imposed in the event of detection.

77. We assess the extent to which these errors may be undesirable on fairness grounds infra in Part III.A. We limit our analysis here to the desirability of the behavioral consequences that flow from these errors and from the advice that corrects them. 
Kaplow and Shavell are thus wrong, we think, to conclude that advice about sanctionability is always desirable. ${ }^{78}$ Because optimizing behavior also involves adjusting the scope of rules that define sanctionable conduct, advice about the scope of rules will often have undesirable effects. Such advice might, for example, teach clients how to exploit tax loopholes. Or such advice might discourage clients from productive endeavors because they learn of unduly harsh tax consequences. Similarly, Kaplow and Shavell are wrong, we think, to conclude that advice about the level of appropriately set expected sanctions is always desirable. Because even the optimal levels of expected sanctions will over- and underdeter, disseminating accurate information about them will often lead to undesirable consequences. Nor, once one admits the possibility of imprecision in sanctions, does there seem any justification for a categorical distinction between advice about the scope of sanctionable conduct and advice about the level of expected sanctions.

The fact that advice about the scope or level of optimal expected sanctions has undesirable as well as desirable consequences does not, however, mean that on balance such advice has ambiguous social value. If society sets sanctions to optimize behavior when those sanctions are known by actors, then, unless the distribution of unadvised ignorance is skewed, the net behavioral consequences of advice that corrects misperceptions about expected sanctions will tend to be socially desirable. The reason is that an optimal sanctioning regime by definition minimizes the adverse consequences of underdeterring undesirable conduct and overdeterring desirable conduct. Accordingly, any actual increase or decrease from the optimal level in expected sanctions for potentially sanctionable actions would cause more harm in terms of reduced desirable or increased undesirable actions than good in terms of reduced undesirable or increased desirable actions. ${ }^{79}$ Generally, over- or underestimations of optimal expected sanctions should disturb this social balance in the same way as actual increases or decreases that move expected sanctions away from optimal levels. Advice that corrects such over- and underestimations should accordingly have net beneficial behavioral effects.

Of course, one might assume that the legal regime would adjust actual sanctions to account for any increased legal ignorance resulting from a general restriction on legal advice. The relevant comparison would then be between (1) a regime with advice and those sanctions

78. See supra text and notes accompanying notes 58-60.

79. "Harm" and "good" here are measured under whatever scale - deterrence, compensation, retribution, and so forth - is used to derive the optimal sanctioning tradeoff. 
that would be optimal for advised individuals, and (2) a regime with the restriction on advice and those sanctions that would be optimal for less-advised individuals. Sanction adjustments for unadvised ignorance would not, however, alter our general conclusion about the overall desirability of advice unless that unadvised ignorance was systematically skewed. Indeed, in some respects sanction adjustments for unadvised ignorance highlight a consideration which strengthens our general conclusion about the overall desirability of providing advice. Namely, unadvised individuals are likely to have more varied and disparate estimates of expected sanctions than advised individuals. This greater individual variation for unadvised actors will increase the over- and undersanctioning of any sanctioning scheme, no matter how much sanctions are adjusted. ${ }^{80}$ The effect of advice in reducing this individual variation thus bolsters our general conclusion that advice about the level of expected sanctions tends to have desirable behavioral effects.

Our general conclusion does, however, have two important exceptions worth emphasizing. First, and most obviously, if sanctions have not been set to optimize behavior, it will be ambiguous whether the net behavioral consequences of correcting over- and underestimations will be socially desirable. Second, misperceptions can be socially desirable if those who would act undesirably are systematically more prone without advice to overestimate expected sanctions (or less prone to underestimate expected sanctions) than those who would act desirably. Absent such a systemic divergence in unadvised perceptions, however, misperceptions of expected sanctions that optimize behavior will have net behavioral consequences that are negative. Legal advice that corrects those misperceptions will accordingly have net behavioral consequences that tend to be socially desirable, even though many specific behavioral consequences are undesirable.

\section{Advice That Alters the Level of Expected Sanctions}

Legal advice given before conduct can help actors alter the level of expected sanctions by advising them how to engage in the contemplated conduct in ways that lower the probability or magnitude of sanctions. Advice can help parties create or produce information suggesting that the contemplated conduct is not sanctionable. Advice can, for example, also help parties prevent the creation or disclosure of information suggesting that the conduct is sanctionable.

80. See supra section I.B.4. We are indebted to David Friedman of the University of Chicago for this point. 
Such advice will have undesirable consequences to the extent it lowers expected sanctions for undesirable conduct. For example, a lawyer may advise a party who is claiming an unwarranted deduction to lower the chance of detection by claiming that deduction on a line of the return less likely to raise suspicion. Or a lawyer may lower the chances of a business being found liable for price fixing by advising a business not to commit to writing any price discussions with its competitor.

But in a regime in which sanctions deter optimally, rather than perfectly, some desirable conduct will also face positive expected sanctions. Accordingly, advice that lowers expected sanctions can also benefit persons whose proposed conduct is desirable: legal advice can help sheep, as well as wolves, to dress in sheep's clothing. For example, advice may inform a party who plans to take a valid tax deduction that a particular means of recording her expenses will minimize the chances her deduction will mistakenly be denied. Or a business that plans to engage in a legal exchange of industry-wide aggregate price information may be advised to make those exchanges only in writing so that unjustified allegations of secret price fixing are harder to make.

These observations establish that the overall effect of advice that lowers expected sanctions is not necessarily harmful in general. Might such advice be generally beneficial? A first step in answering this question is to observe that actors receiving advice that enables them to lower their expected sanctions for engaging in conduct do not act in isolation. Other actors, even those lacking legal advice, can sometimes take steps ex ante that increase the level of expected sanctions for such conduct. And if those other actors have legal advice, the first actor will face an even greater increase in expected sanctions, which will affect both desirable and undesirable conduct. In such cases, one cannot assess in isolation the effect of ex ante advice that allows an actor to create or produce favorable information about contemplated conduct and to prevent the creation or disclosure of unfavorable information. The net effect of such advice depends on whether other persons with an interest in the matter can also influence, ex ante, the creation or disclosure of information that affects the conduct's expected sanctions.

When, for example, both parties to a contract receive advice about how best to evidence their intent in the written contract, this bilateral advice should generally improve the ability of tribunals to distinguish the desirability of the parties' conduct. The reasons for this conclusion parallel those underlying the similar conclusion we drew in a prior article about bilateral litigation advice that influences the infor- 
mation presented about past conduct. Such bilateral litigation advice, we there concluded, should generally improve both the quality and quantity of information reaching the tribunal by enabling each party to screen out irrelevant information, produce more jointly available information, identify more information in investigation, and decrease unlawful withholding and suppression by its opponent. ${ }^{81}$ The net result, we argued, is that, as compared with the situation in which both parties lacked advice, sanctions would generally decrease for desirable conduct and increase for undesirable conduct. ${ }^{82}$

In contractual settings, ex ante bilateral advice that influences the information that would reach the tribunal if contemplated conduct were to become the subject of litigation should have similar effects. Consider two important goals of contract law: ensuring an accurately priced transaction by encouraging the identification and disclosure of relevant information and, in long-term contracts, reducing opportunistic behavior. In a negotiation for the sale of an asset when neither party is represented by counsel, one might expect that the parties' written agreement (if any) would describe the essential elements of the transaction less accurately, specify the information relevant to accurate pricing less clearly, and contain less effective prohibitions on opportunistic behavior than an agreement negotiated by lawyers. Consequently, a tribunal required to resolve a dispute about the transaction is more likely to make errors both in failing to sanction undesirable conduct and in sanctioning desirable conduct.

If only the seller were represented, one would instead expect that legal advice about how to conduct the negotiations and to word the agreement would tend to lower the seller's expected sanctions for failing to disclose information or for opportunistic behavior. When both buyer and seller have attorneys, however, lawyers will prepare and negotiate written warranties, covenants, and other provisions whose principal ex ante effect is to increase expected sanctions for misrepresentation and strategic behavior. ${ }^{83}$ One can therefore expect contracts negotiated by parties with legal advice generally to be more accurately

81. See Bundy \& Elhauge, supra note 33, at 335-61.

82. Id. at 381-82.

83. Cf. Ronald J. Gilson, Value Creation by Business Lawyers: Legal Skills and Asset Pricing, 94 YALE L.J. 239 (1984). Gilson's account suggests that, when business lawyers are on both sides of the transaction, they typically participate heavily in negotiations over provisions designed to increase the seller's expected sanctions for nondisclosure in the form of representations, warranties, and indemnification agreements. Id. at 267-87. They also help draft agreements to control strategic behavior in long-term transactions. Id. at 265-67 (discussing earnout formulas). 
priced and less vulnerable to opportunistic behavior than transactions negotiated by unrepresented parties.

Suppose, however, that a severe imbalance exists in the quality of advice received, that other affected parties lack advice altogether, or that other affected parties cannot observe an actor's conduct or influence the information created and preserved about that conduct. The paradigm cases here might be a form contract of adhesion drafted by lawyers for a large corporation for use in consumer transactions or a decision by taxpayer to document a deduction. In such cases, advice will tend unilaterally to lower expected sanctions for both desirable and undesirable contemplated conduct.

For reasons we discussed in our prior article, in such circumstances the increase in favorable information created or disclosed about conduct will still tend to exceed the decrease in unfavorable information. ${ }^{84}$ Various factors contribute to this result. First, even when other actors have no access to information held by the party receiving advice, advice should still enable the party to classify more information as relevant and to identify more information to create, produce, document, or preserve. Second, for any advice given, the lawyer's own susceptibility to sanctions for nondisclosure should, when an applicable law requires disclosure, result in the disclosure of additional information. ${ }^{85}$ Finally, for any set of information that can be created or disclosed by either party, advice about information selection can increase the favorable information created or disclosed from this set more than it can reduce the unfavorable information created or disclosed.

This informational conclusion has behavioral relevance because there will tend to be more favorable information that can be created, preserved, or produced about desirable conduct than about undesirable conduct. For example, a taxpayer will normally have or be able to document more evidence to support a justified deduction than an unjustified one. As a result of these factors, unilateral conduct advice should decrease expected sanctions for desirable conduct somewhat more than for undesirable conduct.

In some cases, though, the desirability of this differential effect on expected sanctions may turn on whether the regime can (and does)

84. See Bundy \& Elhauge, supra note 33, at 335-61, 373-74, 383-85 (describing the effects of unilateral advice).

85. Id. at 352-55 (discussing effect in litigation of lawyers' special susceptibility to sanctions); cf. Kraakman, supra note 33, at 82-83 (discussing due diligence review by attorneys under $\S 11$ of the Securities Act of 1933). Moreover, because attorneys and law firms are repeat players, they may have reputational interests in being more forthcoming than their clients might wish. 
adjust expected sanctions to take account of the effects of unilateral advice. ${ }^{86}$ Since legal advice may reduce the detectability of both desirable and undesirable conduct, transactions involving lawyer participation may require additional investments in enforcement resources. Alternatively, the regime might increase actual sanctions for legally advised parties to offset the decline in expected sanctions for undesirable actors, without fully offsetting the decline in expected sanctions for desirable actors. Or actual sanctions might be increased to offset the decline in expected sanctions for desirable actors while resulting in a net increase in sanctions for undesirable actors.

Significantly, many legal rules do in fact require or permit the tribunal to adjust the sanctions applicable to disputed nonlitigation transactions in order to disfavor a party whose greater legal sophistication actually or presumptively enabled it to exercise disproportionate influence on the information reaching the tribunal about the transaction. Examples include the strict rules of fairness governing business transactions between lawyers and clients; ${ }^{87}$ the rules governing the construction and application of insurance policies, which strongly favor policyholders; ${ }^{88}$ and the doctrine of unconscionability, which gives explicit weight to differences in the transacting parties' legal sophistication. ${ }^{89}$ Similarly, on the reasonable assumption that the party with better access to a lawyer is more likely to take charge of drafting, the general rule that contracts should be construed against the drafter may also reflect this approach.

Still, in some instances unilateral ex ante advice that lowers expected sanctions will not have beneficial net effects. This is most likely, we think, for cases in which the marginal returns to legal advice diminish more sharply for desirable conduct than for undesirable conduct. ${ }^{90}$ This can occur because, even in an imperfect regime of sanctions, expected sanctions for desirable conduct are often much lower than those for undesirable conduct. For example, an unadvised taxpayer taking a lawful deduction may face much lower expected sanctions than an unadvised taxpayer taking an unlawful deduction.

86. See Bundy \& Elhauge, supra note 33 , at 386-91.

87. See, e.g., Model Rules of Professional Conduct Rule 1.8(a) (1992).

88. See Friedrich Kessler et AL., Contracts: CASES AND MATERIALs 625-634 (3d ed. 1986).

89. See UNIF. CONSUMER CREdTT Code $§ \S 5.108(4)(e)$, (5)(c), 7 U.L.A. 168 (1974); see also Melvin A. Eisenberg, The Bargain Principle and Its Limits, 95 HARv. L. Rev. 741, 763-73 (1982) (proposing and defending a limit on the enforcement of bargained promises in cases of "transactional incapacity").

90. For discussion of this phenomenon as it applies to advice given in litigation, see Bundy \& Elhauge, supra note 33, at 384-85. 
Consequently, even though there may be a greater number of taxpayers helped by advice about lawful deductions, there is greater potential for advice to improve the situation of the would-be violators.

The risk that marginal returns to advice will diminish more sharply for desirable than undesirable conduct depends in important part on the precision of the sanctioning regime. In a regime designed so that desirable conduct never faces positive expected sanctions, ex ante advice can never lower sanctions for desirable conduct; advice for undesirable conduct will always have higher marginal returns. In effect, Shavell assumes such a regime as the basis for his conclusion that all ex ante advice that lowers expected sanctions is undesirable. But we can now see that this regime represents the limiting case for the desirability of such advice, rather than the paradigm case.

Accordingly, unlike Kaplow and Shavell, we do not think that advice that helps parties lower the actual level of expected sanctions for contemplated conduct is always undesirable, even if sanctions are optimally set. Such advice is often socially desirable. Indeed, advice that lowers sanctions generally tends to have desirable effects. To be sure, this tendency may depend on the ability of other parties to influence sanctions and on the ability of the sanctioning regime to adjust sanctions. There will also be cases where, due to diminishing marginal returns from advice, the net effects of unilateral advice clearly favor undesirable conduct. In such cases, restrictions on advice that lowers expected sanctions may well be justified. But there is no justification for drawing a sharp categorical distinction between advice that simply communicates the level of expected sanctions and advice that alters that level.

\section{Conclusion}

Although the work of Kaplow and Shavell has greatly advanced the economic modeling of legal advice, we are forced to disagree with their conclusions about the desirability of different categories of legal counseling. The differences in conclusions stem from differences in assumptions. Although not explicit in their work, Kaplow and Shavell have implicitly analyzed the desirability of advice under a regime of "perfect" sanctions that is not only unrealistic but undesirable, even in an ideal world. ${ }^{91}$ The performance of legal advice under such

91. See Part I. A similar difference in assumptions also underlies the differences between our conclusions and some of those reached in Louis Kaplow, Optimal Deterrence, Uninformed Individuals, and Acquiring Information About Whether Acts Are Subject to Sanctions, 6 J.L. EcoN. \& ORG. 93, 109-11 (1990). Kaplow assumes, we think implausibly, that harmless acts are never illegal and never sanctioned, see id. at 96-97, and that "acts not subject to sanctions cause no harm." Id. at $102 \mathrm{n} .13$. In any event, his analysis focuses on a related, but different, issue: 
perfect sanctioning regimes is at best irrelevant. ${ }^{92}$

Worse, such analyses can be misleading if the subtext to the claim that advice about perfect sanctions is desirable is that, if adverse behavioral effects persist, the target of blame and reform should be the sanctioning regime rather than the advice. For advice about optimal but imperfect sanctions, or at least some forms of such advice, may well be undesirable and thus an appropriate target of reform. The relevant question is thus whether legal advice about sanctions is desirable under a regime that, although unavoidably imperfect, at least optimizes behavior in the face of unavoidable imperfection. Only if and when the answer to this question is "yes" can a plausible case be made that the best target of reform is not legal advice but any nonoptimal sanctions.

One must, however, take into account that the option of reforming the regime of sanctions will not always be feasible. Sometimes the lawmaking process is too sloppy or biased to optimize sanctions: special interests may, for example, have "captured" the legislature. ${ }^{93}$ Other times even perfectly conscientious lawmakers cannot assure optimal sanctions. The definition of sanctionable conduct may lag behind societal changes. Transaction costs may prove significant: the costs of defining sanctionable conduct (including the cost of securing legislative action) may exceed the benefits of a more optimal definition.

More fundamentally, society may choose not to optimize sanctions solely in terms of their behavioral effects. It may regard mistaken sanctioning as inherently wrong because it punishes the innocent or

whether and why ignorance of the law should or should not be a defense or basis for adjusting legal sanctions. Id. at 114-17.

92. In a more recent piece, Kaplow and Shavell do analyze the desirability of advice given tribunal error, concluding that advice about tribunal error in strict liability cases is always socially undesirable. Kaplow \& Shavell, supra note 75 , at 308, 312-14. They reach this conclusion, however, for two reasons.

First, they assume that sanctions serve solely as a price tag that measures the harm inflicted by the given conduct, making conduct desirable if and only if the private benefits exceed the "price," that is, the social harm measured by appropriately set sanctions. Accordingly, in their model an increase or decrease in sanctions from the appropriate level causes more undesirable conduct because the "mispricing" leads either to too much care, if the price is too high, or to too little care, if the price is too low. Although some civil penalties do undoubtedly serve only a price-tag function, Kaplow and Shavell's reasoning is inapplicable when the undesirability of conduct does not depend on the level of private benefits, which we think better describes typical regulation.

Second, Kaplow and Shavell separate advice about the appropriate level of sanctions from advice about trial error. The client who learns about the trial error is thus presumed to already know the appropriate level of sanctions. See id. at 308, 312-13. If one more realistically assumes that ex ante legal advice will simultaneously provide both sorts of advice, then an increase or decrease in the desirability of conduct is possible.

93. See generally Einer R. Elhauge, Does Interest Group Theory Justify More Intrusive Judicial Review?, 101 YALE L.J. 31, 35-44 (1991) (describing interest group theory). 
fails to revenge or compensate injury, or it may take into account direct costs, such as the costs of incarceration. To the extent this is true, optimal sanctions will not be those that optimize behavior, and the overall behavioral consequences of legal advice about optimal sanctions will be ambiguous. When society uses such nonbehavioral measures to judge the social desirability of sanctions, horvever, advice about sanctions similarly should be judged, at least in part, by nonbehavioral criteria. We assess the extent to which such criteria might justify advice about sanctions in section III.A.

\section{The Desirability of Litigation Advice Versus Legal Counseling}

We now return to the claim that the social desirability of litigation advice and primary conduct categorically differ. Recall that this claim takes two forms. The first is Kaplow and Shavell's fifth conclusion: that a "sharp contrast" exists between the "socially desirable character of legal advice offered ex ante" to primary conduct and the "questionable social value of advice offered during litigation."94 The second is the claim, prominently featured in Kaye, Scholer's legal defense, that litigation advice is categorically more desirable than advice about primary conduct. We begin with Kaplow and Shavell's claim.

In prior writing, we have questioned Kaplow and Shavell's analysis of litigation advice from a solely ex post perspective - expressly restricting ourselves, as Kaplow and Shavell did, to the effects of litigation advice on the information presented about past primary conduct. ${ }^{95}$ We there concluded that, even if advised parties pursue opportunities to suppress or withhold information, the overall informational effects of litigation advice will generally help tribunals decide more accurately who should be sanctioned. ${ }^{96}$ Here we challenge the very assumption that evaluating litigation advice should proceed from an ex post perspective.

An initial practical problem facing any categorical distinction between litigation and primary conduct advice is that the two forms of advice overlap to a great extent. Advice during litigation often informs parties about the legal sanctions applicable to future primary conduct. ${ }^{97}$ It seems undeniable, for example, that Kaye, Scholer's representation of Lincoln Savings before the Office of Thrift Supervision,

94. Kaplow \& Shavell, Legal Advice About Information, supra note 4, at 597, 600, 614-15; see supra text accompanying note 71 .

95. See Bundy \& Elhauge, supra note 33, at 319, 349 \& n.84, 402 \& n.223.

96. Id. at $319,335-61$.

97. Kaplow and Shavell's second piece on the subject avoids this problem because it does not distinguish legal counseling from litigation advice but rather distinguishes advice given before conduct from advice given after conduct. See Kaplow \& Shavell, Legal Advice About Acts Al- 
even if fairly characterized as litigation advice, also provided Lincoln with substantial information about ongoing compliance issues. ${ }^{98}$ Further, advice prior to primary conduct often concerns evidentiary issues. It is difficult, for example, to know whether to characterize advice about whether to comply with or breach a contract as directed to primary conduct or to litigation conduct. Indeed, as Kaplow and Shavell concede, ${ }^{99}$ the likelihood of parties obtaining litigation advice ex ante to primary conduct will naturally increase if the law, relying on the supposed sharp contrast, attempts to restrict advice during litigation.

More fundamentally, even classic litigation advice is, like advice prior to primary conduct, actually ex ante advice about the sanctions applicable to contemplated conduct. There are, to be sure, some differences. The contemplated conduct guided by litigation advice is generally not primary conduct but evidentiary conduct, such as investigating, suppressing, withholding, producing, or presenting information in litigation. And the sanctions for misconduct are usually provided not by the laws governing primary conduct, but by the evidentiary sanctions imposed under the rules governing the production of evidence. ${ }^{100}$ But these are differences in form, not substance. Our analysis of advice about sanctions thus applies just as much to advice about evidentiary sanctions as to advice about primary conduct sanctions. Kaplow and Shavell's contrary conclusion ${ }^{101}$ rests not on a comparative analysis of the sanctions applicable to evidentiary versus primary conduct, but rather on a model that abstracts from the existence and effect of evidentiary sanctions. ${ }^{102}$

The problem of imprecise sanctioning is essentially the same for litigation conduct as for primary conduct. As with primary conduct, it is often difficult to determine whether litigation conduct is desirable or undesirable. Withholding and suppression sometimes leave no traces because they occur in private. When a witness "forgets" a conversation, no one can directly observe whether her lack of recall is real

ready Committed, supra note 4 , at 149 . This second distinction is, however, vulnerable to all the other problems discussed in this section.

98. See, e.g., Wilkins, supra note 8, at 1190-91 (describing the potential overlap between litigation and counseling advice in that case).

99. Kaplow \& Shavell, Legal Advice About Information, supra note 4, at 599.

100. Evidentiary sanctions include discovery sanctions and penalties imposed for perjury or refusing to testify. They also include implicit sanctions, such as when a tribunal draws an adverse inference about a party's entire testimony or case when some of her testimony appears false. See generally Bundy \& Elhauge, supra note 33, at 321 (defining evidentiary sanctions).

101. They treat their analysis of advice about sanctions as inapplicable to litigation advice. See Kaplow \& Shavell, Legal Advice About Information, supra note 4, at 597.

102. See id. at 571 . 
or feigned. This means that sometimes undesirable withholding or suppression is indistinguishable from the desirable production of information. The person who truly did not witness or does not remember an event can closely resemble the person who falsely claims not to have done so. The person who accurately claims that he did not intend to kill when he fired the fatal shot will often closely resemble the person who falsely makes the same claim.

Moreover, withholding or suppressing information can be socially desirable. Some withholding or suppression may promote desirable out-of-court conduct or protect against invasions of privacy. ${ }^{103}$ Many evidentiary privileges, including the Fourth Amendment, fall into this category. Other withholding or suppression may promote desirable conduct in litigation. Assertions of attorney-client privilege and workproduct doctrine are said to have this effect. ${ }^{104}$ Finally, withholding or suppression may protect against coercive or unfair tactics by the opponent. In civil actions, this consideration might justify the right to object to unduly burdensome discovery and unfair or misleading cross-examination. In criminal cases, this principle supports the rights guaranteed by the Fifth Amendment. ${ }^{105}$ To the extent it is difficult not only to determine whether withholding or suppression is occurring but also to distinguish between desirable and undesirable forms of withholding and suppression, this further impairs the tribunal's ability to distinguish between desirable and undesirable evidentiary conduct.

As with primary conduct, the legal regime responds to its inability to distinguish with certainty between desirable and undesirable evidentiary conduct with three strategies: (1) sanctioning when certain probability thresholds are met in adjudication; (2) defining the sanctionable conduct using criteria that provide greater certainty but are less closely correlated to social desirability; and (3) adjusting the level of sanctions.

Take, for example, the offense of lying to the tribunal. Sanctioning lies only when they can be detected with certainty may underdeter lying. Indeed, observers generally consider the criminal law of perjury, which demands proof that is close to certainty, to be ineffec-

103. See generally Bundy \& Elhauge, supra note 33, at 349 n.82 (discussing Fourth Amendment).

104. See generally id. at 401-13 (analyzing effects of attorney-client and work-product privileges).

105. See Moran v. Burbine, 475 U.S. 412 (1986); Miranda v. Arizona, 384 U.S. 436, 460 (1966) (stating that a principal purpose of the Fifth Amendment is to protect against government coercion). The values promoted by the Fifth Amendment might well justify suppression that took the form of apt advice to a nonparty witness that she ought to decline to testify. See Bundy \& Elhauge, supra note 33, at 326 \& n.39. 
tive. ${ }^{106}$ Tribunals may, however, implement a threshold probability strategy by forming ad hoc estimates of the probability the witness has lied based on his demeanor, his motive and opportunity to lie, and other, more reliable evidence about the case. If a threshold probability is met, the tribunal can then sanction the party presenting the testimony by discrediting either the seemingly false testimony itself or other evidence in the party's case that would otherwise seem credible and that may actually be true. ${ }^{107}$ The tribunal may also increase or reduce the severity of the sanction imposed at final judgment to punish a party who, it believes, has knowingly presented false testimony. ${ }^{108}$ The lower the threshold probability required to trigger such sanctions, the more desirable evidentiary conduct (truthtelling) will be sanctioned; the higher the probability, the more undesirable evidentiary conduct (lying) will go unsanctioned.

Alternatively, lawmakers may apply a more broadly framed rule. Such a rule might, for example, disqualify parties or other interested persons as witnesses in all cases. English and U.S. law formerly pursued versions of this approach in both civil and criminal cases. ${ }^{109} \mathrm{~A}$ more narrow version of such a rule might disqualify interested parties from testifying only when their testimony is especially hard to verify. The "Dead Man's Act," which bars the survivor of a transaction with a deceased person from testifying against that person's estate, illustrates this principle. ${ }^{110}$ Either effort to redefine the sanctionable conduct will plainly be under- and overinclusive: the rule will not sanction lying by persons who fall outside the disqualified categories, and it will prevent both true and false testimony from persons who are disqualified. ${ }^{111}$ Principally for this reason, the Supreme Court rejected broad rules of testimonial disqualification as unconstitutional in criminal cases. ${ }^{112}$

Finally, the tribunal may not wholly discredit or disallow testimony but instead may discount apparently unreliable testimony by the

106. See FranK, supra note 1 , at 85 .

107. 3A JoHn H. Wigmore, Evidence $§ 1010$, at 983 (John H. Chadbourn rev. ed. 1970).

108. For example, judges may increase the sentence of convicted defendants whom they believe testified falsely at trial. The Supreme Court held this practice consistent with both federal sentencing law and the Constitution in United States v. Grayson, 438 U.S. 41 (1978).

109. 2 WIGMORE, supra note $107, \S 576$.

110. See id. § 578, at 819-20 (citing Owens v. Owens's Admr., 14 W. Va. 88, 95 (1878); Louis's Admr. v. Easton, 50 Ala. 470, 471 (1874)).

111. Indeed, those who attack disqualification on the ground of interest do so on precisely this ground. 2 WIGMORE, supra note $107, \S 578$, at 821 .

112. The Supreme Court has rejected these rules as applied to both defendants, Rock v. Arkansas, 483 U.S. 44, 61-62 (1987); Ferguson v. Georgia, 365 U.S. 570 (1961), and codefendants. Washington v. Texas, 388 U.S. 14 (1967). 
probability that it is untrue. This corresponds to adjusting the level of sanctions in a manner that may be optimal, but which undersanctions undesirable conduct and oversanctions desirable conduct. Liars will benefit more than they should, while those who tell the truth will benefit less than they should. The higher the discount, the less the regime will undersanction undesirable evidentiary conduct but the more it will oversanction desirable evidentiary conduct.

Plainly none of these strategies can achieve perfect sanctioning. But there is no evident reason to think that one can make the sanctioning of primary conduct any more perfect. The basic forms of withholding and suppressing information, ranging from murder (of witnesses) to simple nondisclosure, have analogues in primary conduct. In particular, the fact that evidentiary conduct involves disclosure obligations, and hence the risk of undetectable failures to disclose, does not distinguish it from primary conduct, as the extensive regulation of disclosures in securities, tax, environmental, tort, and contract law demonstrates. Indeed, failures to disclose in litigation arguably present an easier problem of detection than some nonlitigation failures to disclose because in litigation the opponent and the tribunal are both alerted to the possibility of wrongful suppression and nondisclosure and have incentives to detect them.

Given the lack of theoretical foundation for the conclusion that litigation advice is categorically less desirable than primary conduct, that conclusion must rest on an empirical claim that current evidentiary sanctions are in fact less perfect or optimal than current primary conduct sanctions. Such an empirical claim seems difficult to sustain. It would require showing how frequently evidentiary sanctions undersanction undesirable conduct or oversanction desirable conduct, and then showing, for representative categories of primary conduct, that the imperfection is lower.

Certainly Kaplow and Shavell's account does not sustain this burden. Their account assumes the existence of a set of information over which a party can exercise control, in the sense that withholding or suppressing the information is not deterred. ${ }^{113}$ But neither the existence of a set of information whose wrongful withholding or suppression is undersanctioned, nor the occurrence of some acts of wrongful withholding or suppression, establishes the comparative superiority of advice about sanctions for primary conduct. After all, expected sanctions for wrongful primary conduct also frequently underdeter undesirable conduct, and wrongful acts of primary conduct occur as well.

113. Kaplow \& Shavell, Legal Advice About Information, supra note 4, at 570-76, 577 n.25. 
Kaplow and Shavell's posited "sharp contrast" between the social value of advice about evidentiary conduct and advice about primary conduct thus rests on a misleading comparison between a regime of evidentiary sanctions that is assumed, but not demonstrated, to be ineffective and a regime of sanctions for primary conduct that is assumed, but not demonstrated, to be perfect.

More fundamentally, the failure of evidentiary sanctions to deter all withholding or suppression cannot be conclusive because such evidentiary conduct is sometimes socially desirable. ${ }^{114}$ To the extent withholding and suppression are desirable, the desirability of litigation advice (and in particular advice about evidentiary sanctions) cannot be judged, as we were willing to do in our prior article, ${ }^{115}$ solely by its effects on the information reaching tribunals. Rather it must be judged by whether it advances overall societal interests - including the interests served by withholding and suppression.

Under this standard, if evidentiary sanctions optimize evidentiary conduct, then litigation advice may well tend to be desirable even when it has a negative effect on the information reaching tribunals. True, such negative informational effects may worsen the regime's ability to sanction the primary conduct that is the subject of litigation. But the regime has no reason to focus exclusively on optimizing primary conduct. Nor, if it chooses to pursue that goal, must it do so exclusively by increasing the accuracy with which adjudication identifies the desirability of primary conduct. ${ }^{116}$ Instead, the regime may aim to optimize the combination of primary and litigation conduct by implementing the sanctioning regime that minimizes the total adverse consequences of undersanctioning undesirable primary and litigation conduct and oversanctioning desirable primary and litigation conduct.

We conclude, therefore, that the claim that advice about evidentiary conduct is systematically inferior to advice about primary conduct cannot be sustained. Both forms of advice will correct over- and underestimations of expected sanctions, with desirable and undesirable behavioral consequences. ${ }^{117}$ Both will overall tend to have desirable

114. See supra section I.A and text accompanying notes 103-05.

115. See Bundy \& Elhauge, supra note 33, at $380-96$ (analyzing desirability solely of the informational effects of advice).

116. See supra section I.A (noting that increased information might itself deter desirable primary conduct).

117. The beneficial behavioral consequences of correcting overestimations of evidentiary sanctions may sometimes be indirect. Take, for example, a party who overestimates discovery sanctions for failing to produce a document they truly do not possess. In the extreme this may deter the desirable production of the information that the party truly does not have the document by tempting the party to create a false document. Perhaps more likely, this may deter the party from engaging in other desirable litigation conduct - such as litigating a legitimate claim or 
behavioral consequences, unless sanctions do not optimize behavior or a systemic divergence exists between the misperceptions of desirable and undesirable actors.

Both types of advice will also help parties take steps, prior to engaging in conduct, to influence the information that will reach the tribunal about that conduct. ${ }^{118}$ In other words, both types of advice will affect the level of expected sanctions. When both parties seek to shape the information that will reach the tribunal, this effect should be desirable. ${ }^{119}$ One might, if anything, expect this desirable result more often in the litigation context, in which parties know and have focused on their adversary, than in the nonlitigation context, in which affected parties often do not know or monitor the parties who injure them. When only one party acts to shape the information that will reach the tribunal, advice should also tend to be desirable, although this may depend in part on the regime's ability to adjust sanctions. ${ }^{120}$

This framework also makes it possible to show why the claim that litigation advice is categorically more desirable than advice about primary conduct, while seemingly plausible, ultimately fails as well. The core of that claim rests on the presence in open court of a legally advised adversary and a tribunal. Their presence, the argument goes, greatly reduces the lawyer's concern that his advice and assistance will have harmful consequences. Because concealment and fabrication of evidence are more likely to be detected and sanctioned, his advice about the level of expected sanctions will tend to deter it. Moreover, because of the presence of the opponent, the lawyer need have no fear that his advice about how to lower sanctions for withholding or fabrication of evidence will result in net harmful consequences because the opposing counsel's advice will tend to neutralize it. ${ }^{121}$ In contrast, in nonlitigation counseling situations, the observing opponent, her lawyer, and the tribunal are absent. ${ }^{122}$ In consequence, the counselor who provides full advice, either about the level of expected sanctions

defense or presenting other information - that seems likely to lead to a request for a document. Deterring such litigation conduct will skew sanctions for primary conduct.

118. Legal counseling will affect the information that reaches the tribunal about contemplated primary conduct in the ways described supra in section II.B.2. Litigation advice will affect, in the same ways, information that reaches the tribunal about contemplated litigation conduct. It will also affect the information that reaches the tribunal about past conduct in the ways described in Bundy \& Elhauge, supra note 33, at 335-61.

119. See supra text accompanying note 81 .

120. See supra text accompanying notes 84-86.

121. Wilkins, supra note 8 , at $1184 \&$ nn.159-60 (outlining and apparently endorsing this claim, at least when there is no substantial imbalance in the advice available to the parties).

122. See id. at 1188 (in the "prototypical counseling situation," only one party is present and represented by counsel). 
or how to lower them, runs a greater risk of facilitating undesirable conduct.

Within our framework of analysis, this claim is most plausible if understood as asserting that ex ante advice that allows a party to lower her expected sanctions (or raise her opponent's expected sanctions) for evidentiary conduct is categorically superior to comparable ex ante advice for primary conduct. As we have shown, there is no reason to believe that the scope or level of expected evidentiary sanctions, uninfluenced by advice that potentially lowers (or raises) those sanctions, is any more optimal than the scope or level of similarly uninfluenced primary conduct sanctions. Nor is there any strong reason to think that parties' estimates of expected evidentiary sanctions are more likely to be systematically skewed in ways that produce desirable behavioral effects. If advice about the scope and level of evidentiary sanctions is categorically superior to advice about the scope and level of primary conduct sanctions, therefore, it must be because advice about how to influence the level of expected sanctions in litigation is categorically more likely to move the overall level of expected sanctions to optimal levels than is advice outside of litigation.

Understood as a claim about the effects of advice that lowers expected sanctions by creating, producing, or concealing information about evidentiary conduct, the claim for the superiority of litigation advice contains a core of persuasive insight. As we have seen, such advice is generally more likely to be beneficial to the extent that another interested actor can observe the party's conduct and still more beneficial to the extent that the observer has legal advice. In a wellrun courtroom - where both parties are aware of each other's motives, can observe each other's evidentiary conduct, have lawyers, and can resort to the tribunal for prompt rulings on disputed questions one might therefore expect that advice about how to lower one's own evidentiary sanctions (or raise one's opponent's) will often have desirable effects.

The force of this insight, however, leaves us a long way from a categorical distinction between nonlitigation and litigation advice. We need to know more about the relative frequency of these conditions in litigation and nonlitigation settings. The argument would be easy if in litigation evidentiary conduct were always observable, both sides always had competent counsel, and the tribunal was always present, while interested actors rarely observed primary conduct or rarely had legal advice. ${ }^{123}$ But this is not the case. Evidentiary conduct varies

123. Fuller's account, which contrasts the conduct of competent paired advocates "in open 
sharply in the extent to which it is subject to observation by the opponent. Lawyers' arguments and direct testimony can be closely observed, but most trial preparation cannot. Moreover, much litigation features severe imbalances in parties' legal advice.

Conversely, in many cases in which an actor receives advice about how to lower expected sanctions for primary conduct, that conduct is subject to observation by someone who has a substantial incentive to monitor the actor's conduct and increase his sanctions for any undesirable conduct. This will be true, for example, in most contractual settings and in many regulatory settings. Much of the conduct that Kaye, Scholer was charged with assisting, for example, was observable, and observed, by the Bank Board. ${ }^{124}$ Often that observer will have legal advice. Indeed, the situation in which all interested participants, including government regulators, have advice is probably typical of most complex transactional and regulatory work.

Thus in both litigation and nonlitigation settings, there will be many occasions in which advice about how to lower expected sanctions for engaging in conduct will be strongly desirable because there is a high likelihood that the conduct can be observed, that the observer will be interested, and that the observer will have comparable competent legal advice. In both settings, there will also be occasions when one party has a disproportionate influence on the information that will reach the tribunal, either because the actor receiving advice controls more information about the conduct or has better legal advice; in these cases the desirability of advice will sometimes depend on the regime's ability to adjust sanctions.

Finally, in each setting there will be occasions when sanctions cannot be adjusted to take advantage of increases in information resulting from the provision of advice or when advice simply reduces sanctions more for undesirable than for desirable conduct. Absent some reason to think, however, that situations of the last type are more common when advice is given outside the litigation setting, a categorical claim for the superiority of litigation advice cannot stand.

\section{NonCATEgorical Restrictions on ADVICE}

We have identified two main classes of advice about expected sanctions that have undesirable effects on the behavior of recipients. First, parties who learn that expected sanctions for desirable conduct are

court" with the conduct of a single lawyer offering "quiet counsel" in the privacy of his own office, typifies this view. Fuller \& Randall, supra note 7, at 1161.

124. See Wilkins, supra note 8, at 1173 \& n.116 (describing such a situation). 
higher than they thought will be led to refrain from desirable conduct. Second, parties who learn that expected sanctions for undesirable conduct are lower than they thought, or who get advice about how to lower them, will sometimes be led to engage in undesirable conduct. If the legal regime could reliably identify actors who tend to make socially desirable mistakes about expected sanctions, selectively denying them advice would improve the optimization of over- and underdeterrence. In section III.A we argue that, even if such targeted denials could be made accurately, they would often conflict with principles of fairness. In section III.B we address the problem that efforts to deny advice that produces undesirable consequences will also deter or deny desirable advice.

\section{A. Fairness Justifications for Advice with Adverse Behavioral Consequences}

The fairness claim is clearest in the case of those who would forgo desirable acts if advised about the true risk of sanctions. Denying such persons advice would penalize them not because they are potential lawbreakers, but because (without advice) they would engage in more desirable conduct. To allow such persons to proceed in ignorance is unfair because it violates the principle that "one should be able to know of the law in order that one can obey it."125 Denying them advice also returns evil for good because it increases both the likelihood that the person will act as society wishes and the likelihood that society will punish the person. In a just regime, it may sometimes be inevitable that those who act desirably will face a risk of sanctions. But it is hard to see how it can be just to impose this risk on desirable actors when they have been denied a reasonable opportunity to obtain knowledge that would have prevented them from engaging in the conduct subject to the risk of sanctions.

These principles do not justify giving advice when it would cause persons to engage in undesirable acts, assuming that such persons can be identified. For example, actors who would steal from others if accurately advised that the risk of punishment was lower than they thought cannot plausibly claim unfairness if they are denied such advice. ${ }^{126}$ It might be argued that even those who predictably will engage in wrongdoing if fully advised are entitled to advice as a matter of

125. Kaplow \& Shavell, Legal Advice About Information, supra note 4, at 609. Because of what we argue is their false distinction between legal counseling and litigation advice, Kaplow and Shavell conclude that this principle justifies advice about primary conduct but not advice about litigation conduct. Id. at $609 \&$ n.113.

126. Cf. Dan-Cohen, supra note 14, at 672 ("If the individual's actions fall outside the sphere of autonomy he cannot complain of a deprivation of autonomy, when he discovers that the fear 
personal autonomy or dignity. But such claims have questionable force when the actor is an organization, rather than an individual.127 More fundamentally, it is difficult to frame an attractive conception of individual autonomy that would justify such advice, at least when the undesirability of the resulting conduct is sufficiently clear and its likelihood sufficiently high. ${ }^{128}$ The autonomy claim is especially problematic if, as is usually the case, the undesirable conduct harms innocent actors because then the claim amounts to favoring the autonomy of the undesirable actor to commit harm over the autonomy of the innocent actor to be free of undesirable harm.

As a general rule, then, it is not unfair to deny advice to an actor when the legal system can be certain that the advice would lead him to engage in undesirable conduct. But some persons denied advice on that ground may have a claim of unfairness if other persons have, or can obtain, knowledge about sanctions for undesirable conduct that enables them to harm the person denied advice.

The supposed obligation to tell the "the truth, the whole truth, and nothing but the truth" illustrates the point. Ostensibly, this oath obligates witnesses to volunteer information. In fact, although a literal violation of the oath, a party who is not asked about certain information can legally fail to volunteer it. Suppose, however, that an unadvised party believes the oath and volunteers information on the assumption that failure to comply with the oath will be detected and

that shaped his conduct was excessive and that $\ldots$ he could have violated his duty with impunity.").

127. See, e.g., Deborah L. Rhode, Ethical Perspectives on Legal Practice, 37 STAN. L. REv. 589, 607-08 (1985) (corporations lack claim to individual autonomy). See generally MEIR DANCohen, Rights, Persons, and Organizations: a Legal Theory for a Bureaucratic SOCIETY (1986) (same).

128. See, e.g., Dan-Cohen, supra note 14, at $671-72$ (arguing that keeping a would-be wrongdoer in ignorance does not infringe Kantian autonomy). Perhaps for that reason, those who found the right to advice on autonomy or dignity normally would not extend that right to persons who will certainly use advice to engage in undesirable conduct. Instead they argue that lawyers should not too readily conclude either: (1) that any particular class of conduct is undesirable, see MonRoe H. Freedman, LAWYers' ETHics IN AN AdVERSARY SYSTEM 51-57 (1975); Alan Donagan, Justifying Legal Practice in the Adversary System, in THE GOOD LAWYER 123, 126-33 (David Luban ed., 1983); or (2) that any particular client, if fully advised, would in fact engage in such conduct. See, e.g., MONRoe H. FreedMan, Understanding LawYERS' ETHICS 159 (1990) (arguing that a lawyer giving advice should not assume that the client when advised will engage in wrongdoing, even if the client has a strong incentive to do so).

These more limited positions are not necessarily inconsistent with the account offered here. To the extent they treat freedom of choice as a positive good that can render otherwise undesirable conduct desirable, they can be incorporated into a system of optimal sanctions that gives independent weight to party autonomy. See supra section I.B. To the extent they claim that lawyers will make mistakes about whether conduct is undesirable or whether the client, if advised, will engage in it, they imply that full advice is more likely to produce desirable than undesirable conduct. 
heavily sanctioned. Such a party will often be victimized by an opponent who understands and acts upon the real rules.

If society is not prepared to invest what is required to deter the wrongful conduct of those who are already knowledgeable, fairness may require allowing both parties to learn and act upon the real rules of the game. We might tentatively state this disturbing principle in this way: when (1) undesirable litigation conduct is not sanctionable, or, though technically sanctionable, is not in fact sanctioned, and (2) one can confidently predict that one party, given its incentives and level of knowledge, will engage in such conduct, then depriving the opposing party of knowledge that would enable him to engage in comparable conduct is unfair.

This same principle can sometimes apply to advice about primary conduct. For example, suppose two sellers get advice that lowers their expected antitrust sanctions for a merger that will give them monopoly power and allow them to raise prices. In those circumstances, a group of buyers may have a fairness claim to advice that lowers their expected antitrust sanctions for forming an anticompetitive buying association that will give them countervailing market power.

Common sense and common morality both suggest that this "fair fight" principle has limits. Because in its pure form the principle rests largely upon an intuition that equal treatment is inherently fairer, rather than upon any discernable improvement in social welfare, its normative force seems relatively weak. It hardly justifies advice that results in harm to nonparties or to those who are not engaging in undesirable conduct that injures the party. It also may not justify advice that will lead to plainly wrongful conduct, such as perjury or bribery. Most important, the principle does not apply if sanctions for the opponent's undesirable conduct are available and reasonably effective, because then the first premise for the application of the principle fails. This will often be the case when, as the second premise requires, one can confidently predict the opponent's undesirable conduct. If the opponent's predictably undesirable conduct remains effectively unsanctioned, then a reform in sanctions would ordinarily seem justified.

Nonetheless, the fair fight principle might justify a variety of advice about sanctions that causes parties to engage in undesirable but underdeterred conduct. Fair fight arguments may, in fact, often extend beyond fairness. For example, in the countervailing power example, forming the buying association may be a "second-best" solution that will result in more efficient prices and outputs than would result if 
only the sellers had monopoly power. ${ }^{129}$ Likewise, consider again the obligation to tell the whole truth. Now assume that the tribunal has already adjusted sanctions to reflect the general understanding among litigants that information should not be volunteered but has not adjusted sanctions to compensate for the fact that one of the litigants does not have legal advice. Given these assumptions, the tribunal will often assume that the unadvised litigant is not volunteering information, even when she in fact is being forthcoming. In such cases the unadvised litigant has more than a fairness claim to advice: she can claim that more accurate adjudication will result if both parties have advice that corrects overestimations of sanctions for undesirable withholding than if only the opponent does.

In short, if an opponent predictably engages in undesirable conduct, ordinarily undesirable primary or evidentiary behavior - such as anticompetitive combinations or withholding information - may become desirable. In these circumstances the desirability of advice that lowers or corrects overestimations of sanctions for the conduct in question is not paradoxical: the advice is desirable because the ostensibly undesirable conduct is in fact desirable. ${ }^{130}$

\section{B. The Overdeterrence Problem with Restricting Undesirable Advice}

Traditional regulation of legal advice allows much advice with undesirable behavioral consequences. Lawyers cannot "counsel a client to engage, or assist a client, in conduct that the lawyer knows is criminal or fraudulent."131 But the professional rules permit lawyers to advise clients whose conduct is not known to be criminal or fraudulent, no matter what the likelihood that the advice will cause undesirable conduct. ${ }^{132}$ This bright-line rule encompasses both neutral "advice" about the scope of sanctionability or the level of expected sanctions

129. See generally Phillip AREeda \& Louis Kaplow, ANTITRUST ANAlysis: Problems, TEXT, CASEs 40-42, 195 \& n.24, 223 n.46 (4th ed. 1988) (discussing countervailing power and second best theory).

130. This insight turns out to be at the core of many defenses of deceptive lawyer tactics in litigation. See, e.g., Simon, supra note 1, at 1100-02, 1108 (arguing that the lawyer should be free to use deceptive tactics when it would promote an informed resolution of the case).

131. Model Rules of Professional Conduct Rule 1.2(d) (1992). The formulation of the prohibition on assistance in the Model Code may be more restrictive, stating that a lawyer "shall not ... [c]ounsel or assist his client in conduct that the lawyer knows to be illegal or fraudulent." MODEL CODE OF PROFESSIONAL RESPONSIBILITY DR 7-102(A)(7) (1980) (emphasis added); see also MOdel CODE of ProfessionAl Responsibility EC 7-5 (1980) ("A lawyer should never encourage or aid his client to commit criminal acts or counsel his client on how to violate the law and avoid punishment.").

132. Lawyers have some freedom not to provide advice, either by declining to accept a client, negotiating express limitations on the scope of the representation, MODEL RULES OF ProfesSIONAL CONDUCT Rule 1.2 (c) (1992), or withdrawing if the lawyer "reasonably believes" the 
and more active "counsel or assistance" designed to reduce expected sanctions.

For conduct "known" to be a crime or fraud, the professional rules eschew a bright-line approach. Although forbidden from "counseling" or "assisting," the lawyer remains obliged to provide full advice. But the line between forbidden assistance and required advice is fuzzy. At one extreme, clearly a lawyer can state that the contemplated conduct is unlawful and need not automatically withdraw even if the client insists on engaging in the conduct. ${ }^{133}$ Equally clearly, at the other extreme, a lawyer may not physically assist in the consummation of the criminal or fraudulent act. ${ }^{134}$ In between, the rules purport to recognize a "critical distinction between presenting an analysis of legal aspects of questionable conduct and recommending the means by which a crime or fraud might be committed with impunity." 135 When clients can readily infer the forbidden "means" from the permitted "analysis," however, the distinction becomes obscure both in theory and practice. ${ }^{136}$ The essential structure of these obligations is the same for litigation as for counseling. ${ }^{137}$

client's proposed conduct to be "criminal or fraudulent" or finds it "repugnant or imprudent." Model Rules of Professional Conduct Rule 1.16 (b)(1), (3) (1992).

Subject to these limitations, however, the rules arguably require lawyers to provide both advice and assistance for much socially undesirable conduct. The obligation to provide full advice is express. See Model Rules of Professional Conduct Rule 2.1 (1992) ("In representing a client, a lawyer shall . . . render candid advice."); see also MODEL RULES OF PROFESSIONAL CONDUCT Rule $1.2 \mathrm{cmt}$. (1992) ("A lawyer is required to give an honest opinion about the actual consequences that appear likely to result from a client's conduct."). The obligation to provide "assistance" within the representation is also express in the MODEL CODE OF PROFESSIONAL RESPONSIBILITY DR 7-101(A)(1) (1980) (a lawyer "shall not intentionally ... [f]ail to seek the lawful objectives of his client through reasonably available means permitted by law") (footnotes omitted), and implicit in the Model Rules, see MODEL Rules of Professional Conduct Rule 1.1 (1992) (obligating lawyers to "provide competent representation to a client"); MODEL RULES of Professional Conduct Rule 1.7 (b) (1992) (obligating lawyers to avoid any conflict of interest - including strong ethical antagonism to the client's proposed course of action - that "may ... materially limit" the representation). The law of legal malpractice might also require such advice. See infra text accompanying notes 182-83.

133. See Geoffrey C. Hazard, Jr., How Far May a Lawyer Go in Assisting a Client in Legally Wrongful Conduct?, 35 U. MIAMI L. REv. 669, 671 (1981) ("The law clearly sanctions providing ... simple, unsuggestive advice...."). Withdrawal would be required only if continued involvement would violate a professional rule. MODEl Rules of Professional Conduct Rule 1.16 (1992).

134. Hazard, supra note 133, at 671 (stating that assistance clearly includes the "lawyer's physical execution of a purpose that the client would like to realize but cannot or will not actually execute himself").

135. Model Rules of Professional CONDUCt Rule $1.2 \mathrm{cmt}$. (1992).

136. See supra text accompanying note 51; Wolfram, supra note 50, $\S 13.3 .2$, at 695 ("[T] he nature of that critical distinction is not made clear."); Charles Wolfram, Mapping the Minefield: The Applicable Ethics Rules and Conflicting Duties in THE ATtORNEY CLIENT RELATIONSHIP, supra note 55, at 53,67 ("'O]nly the most murky guidance on [the divide between counseling and facilitation] is given in reported authority.").

137. For example, Model Rules 3.3 and 3.4(a), (b), which deal with advice and assistance to evidentiary conduct, prohibit only knowing assistance in presenting false evidence or in the un- 
Both academic and regulatory critics of the profession argue that the traditional rules permit too much undesirable legal advice. ${ }^{138}$ For those who take that view, there are two central regulatory possibilities. The first strategy, which we have discussed extensively in our earlier article, ${ }^{139}$ is to establish bright-line rules keyed to aspects of the lawyer-client relationship that can be confidently observed at low cost, rather than to the content and significance of advice in the particular case. These rules intentionally sweep more broadly than the prohibition of advice that knowingly assists crime or fraud on the basis of a generalization about the likely behavioral effects of advice. Examples of such rules include small claims court rules forbidding the use of a lawyer, ${ }^{140}$ rules restricting the amounts that actors can pay for advice, ${ }^{141}$ sequestration orders prohibiting consultation between a witness and his counsel during breaks in cross-examination, ${ }^{142}$ and rules governing the existence, invocation, and waiver of the right to counsel in criminal cases. ${ }^{143}$

As our discussion in Part I shows, such rules are cheap to enforce and easy to comply with. But, as that discussion also indicates and as our earlier article shows in detail, because the rules are based on features of the lawyer-client relationship that relate only loosely to the social value of the advice given, they run severe risks of overdeterrence unless carefully tailored. ${ }^{144}$ It is therefore understandable that their use has been relatively limited.

lawful destruction or fabrication of evidence. Model Rules of Professional Conduct Rules 3.3, 3.4(a), (b) (1992).

138. See, e.g., LUBAN, supra note 9, at 160-61 (arguing that lawyers should "dissociate themselves from projects that are immoral" even when professional rules would permit continued representation); Simon, supra note 1, at 1096 (arguing that current norms "authorize or require a lawyer to act in a way that ... frustrates the most legally appropriate resolution of the matter"). Federal regulatory agencies such as the Securities and Exchange Commission and the Office of Thrift Supervision have expressed similar objections to the present professional rules, and adopted alternative rules or practices. See, e.g., In re Carter \& Johnson, Exchange Act Release No. 17,597, [1981 Transfer Binder] Fed. Sec. L. Rep. (CCH) \ 82,847 (Feb. 28, 1981) [hereinafter Carter \& Johnson]; Order to Cease and Desist and For Affirmative Relief, In re Fishbein, OTS AP-92-24 (Mar. 11, 1992) [hereinafter Kaye, Scholer Order].

139. Bundy \& Elhauge, supra note 33 , at 396-401, 413-19.

140. Id. at 396-97 (discussing such restrictions).

141. Caplin \& Drysdale v. United States, 491 U.S. 617 (1989) (criminal forfeiture which effectively reduced amount that criminal defendant could pay his lawyer does not violate Sixth Amendment); Walters v. National Assn. of Radiation Survivors, 473 U.S. 305 (1985) (limiting the amount which government benefits claimants could pay their lawyers is consistent with due process); Bundy \& Elhauge, supra note 33, at 398-401 (analyzing such restrictions).

142. Perry v. Leeke, 488 U.S. 272 (1989) (upholding such a restriction); see Bundy \& Elhauge, supra note 33, at 413-17.

143. See Bundy \& Elhauge, supra note 33, at 418-19 \& nn.273-77 (analyzing the effects of such doctrines).

144. For an extended discussion of how the risks of overdeterrence limit the use of bright-line restrictions upon ex ante advice to a testifying client about what to say in court, see $i d$. at 413-17. 
Not surprisingly, then, many academic and regulatory critics of the profession are drawn to a strategy of restricting advice based on a case-by-case assessment of its consequences. They would reform professional codes and ethical norms to make prohibitions on advice and assistance broader and more open-textured in three distinct ways. First, they would expand the crime-fraud exception to encompass advice regarding a broader range of client conduct, including conduct that is unlawful or simply socially undesirable. ${ }^{145}$ Second, they would impose liability based not just on attorney knowledge, but also on recklessness or, in some versions, failure to conduct a reasonable inquiry. ${ }^{146}$ Third, they would require that lawyers go beyond refusing to assist undesirable client conduct and actually take reasonable measures to prevent it. ${ }^{147}$ For ease of expression, we will refer to the combination of such expanded legal prohibitions on giving undesirable advice as a "general standard." 148

In this section, we assess this debate between the profession and its critics and analyze the effects of requiring attorneys to deny advice when it seems likely to have undesirable consequences. ${ }^{149} \mathrm{We}$ begin in

145. Those endorsing a standard that approaches social desirability include LUBAN, supra note 9, at 173-74, and Simon, supra note 1, at 1093. Regulatory agencies tend to focus on lawfulness - defined in terms of the spirit or purpose of the law - without regard to whether the conduct is a crime or fraud. See, e.g., Kaye, Scholer Order, supra note 138, ๆ 15(c) (forbidding law firm from acting as counsel in a matter in which the client is "violating any applicable federal banking statutes or regulations, including by attempting to evade any such regulations by elevating form over substance"). A similar statutory standard will apply to lawyers sued under the Financial Institutions Recovery, Reform and Enforcement Act of 1989 (FIRREA), which permits imposition of liability for knowing or reckless participation "in any unsafe or unsound financial practice which is likely to cause more than minimal financial loss." Pub. L. No. 101-73, $\S 204(\mathrm{f})(6), 103$ Stat. 183, 193 (codified at 12 U.S.C. \$ 1813(u)(4) (Supp. IV 1992)).

146. See, e.g., Simon, supra note 1, at 1097 (advocating denials of advice when the "lawyer ... [has] good reason to recognize" that an unjust result will follow from providing it); Kaye, Scholer Order, supra note 138, I 1(b) (" 'knowledge' shall mean actual knowledge or reckless disregard of the facts."); id. at I 12 (imposing a variety of due diligence requirements). The prime example of a diligence obligation for counselors is, of course, that imposed on counsel in a public offering under \$11 of the Securities Exchange Act of 1933.

147. In re Carter, Exchange Act Release No. 17,597, [1981 Transfer Binder] Fed. Sec. L. Rep. (CCH) 1f 82,847, at 84,172 (Feb. 28, 1981) (holding that lawyer must take reasonable measures to prevent unlawful conduct by client); Simon, supra note 1, at 1098, 1100 (lawyer who concludes that advice will result in injustice must take "reasonably available actions" to promote justice and prevent injustice).

148. We recognize that this broadly drawn contrast between a narrow version of the crimefraud rule and the general standard described in text brushes over many intermediate positions. We do this because our purpose is to spell out the implications of a shift toward a general standard, rather than to defend any particular place along the line. For examples of intermediate views focused on the obligations of lawyers for insured financial institutions, compare Wilkins, supra note 8, at 1151-1215 (tending toward a general standard) with Jackson, supra note 53, at 1055-61 (tending toward the normal crime-fraud rules).

149. Other sorts of rules may effectively restrict the flow of advice, including: (1) rules governing the formation of the attorney-client relationship, such as those regulating client solicitation and advertising; (2) rules governing the financing of representation, such as those concerning attorney fees, the sale of claims to lawyers, loans and advances to clients, and public subsidies for 
section III.B. 1 by considering these proposals for a general standard governing the provision of legal advice. We conclude that, although such a general standard would indeed reduce the underdeterrence of undesirable advice, it would also raise grave problems of overdeterrence: preventing or rendering unaffordable much desirable advice. Moreover, this overdeterrence would disproportionately affect clients who are poor, distressed, or inexperienced; who have one-shot or lowstakes claims; or who are from racial or socioeconomic backgrounds different from their lawyers. We then consider in section III.B.2 whether such a general standard would be less problematic if it was embodied in an ethical norm - rather than a legal prohibition against giving undesirable advice. Surprisingly, we conclude that the case for such an ethical norm is not clearly better, and in some respects weaker, than that for the legal prohibition. To the extent such an ethical norm were effective, it too would raise important overdeterrence problems, as well as undermining the standard of care for giving advice under the law of legal malpractice. Finally, in section III.B.3, we reconsider the traditional rule in light of the over- and underdeterrence problem. The traditional rule, we conclude, may well optimize over- and underdeterrence of advice by triggering either a general standard (in crime-fraud cases) or a bright-line rule (outside the crimefraud cases), depending on whether, given the circumstances, overdeterrence or underdeterrence seems the more pressing problem.

\section{A Legal Prohibition on Undesirable Advice}

Proposals for general standards forbidding lawyers from offering advice leading to undesirable consequences have suffered critique on many grounds. Common critiques are that such general standards

legal advice; and (3) rules limiting the right to provide legal advice, such as those governing admission to the profession and the unauthorized practice of law. Although such rules restrict advice, none at present reflects an express policy of suppressing advice on account of its behavioral consequences. Some have argued, however, that some such rules were in the past intended, at least in part, to deter selectively particular kinds of advice, principally advice deemed likely to increase the likelihood of claims by personal injury, consumer, and civil rights plaintiffs. See, e.g., Jerold S. Auerbach, UNEqual JUstice: Lawyers and SOcial Change in Modern AMERICA 41-50 (1976) (arguing that rules on advertising, solicitation, acquiring an interest in litigation, and division of fees among lawyers in the early twentieth century were designed to favor corporate clients); Philip Shuchman, Ethics and Legal Ethics: The Propriety of the Canons as a Group Moral Code, 37 GEo. WASH. L. REv. 244, 262-66 (1968) (same). The desirability and fairness of selective transmission in those settings seems doubtful but in any event is beyond the scope of our discussion here. 
would be unenforceable ${ }^{150}$ and infringe party autonomy. ${ }^{151}$ We do not wish to recanvass this debate, other than to note that proponents of a more general standard have responded to these and other traditional critiques more persuasively than one might suppose. ${ }^{152}$ Rather, we want to emphasize an independent problem with general standards prohibiting undesirable advice that proponents have not addressed: the inevitable propensity of such general standards to overdeter desirable forms of advice. ${ }^{153}$

Thus, without addressing them directly, we put the traditional arguments, and responses to them, aside. With regard to enforceability, we assume that, even if undesirable advice cannot be eliminated, some of it could be deterred by legal sanctions under a standard prohibiting undesirable advice. We further assume that, despite the value of autonomy, some advised misconduct falling short of known crime or fraud remains socially undesirable, if only because such misconduct infringes on the autonomy of others. On these assumptions, we think that overdeterrence concerns provide an important reason to be wary of general standards that seek to prohibit undesirable forms of advice.

The risk that a general standard would overdeter desirable advice flows from two basic sources: (1) increased compliance costs; and (2) increased expected sanctions for providing desirable advice. A general standard will significantly increase compliance costs for several reasons. The due diligence obligation under such a standard would require more extensive investigation in a broader range of cases. Moreover, a general standard makes a broader range of information potentially relevant to attorney liability. When the issue is whether the advice will lead the client to do something undesirable, such information will include what the client knows, how the client would act with and without legal advice, the consequences of those courses of action, and, under broader formulations of the standard, which of the two courses of action is more socially desirable. When the issue is the

150. See, e.g., James J. White, Machiavelli and the Bar: Ethical Limitations on Lying in Negotiation, 1980 AM. B. FouND. RES. J. 926, 937-38 (discussing proposed requirements of fairness and candor in negotiation).

151. See, e.g., Donagan, supra note 128, at 133; Stephen Pepper, The Lawyer's Amoral Role: A Defense, a Problem and Some Possibilities, 1986 AM. B. Found. RES. J. 613.

152. See, e.g., Robert W. Gordon, The Independence of Lawyers, 68 B.U. L. REV. 1 (1988); Rhode, supra note 127; Simon, supra note 1, at 1119-44.

153. Many considerations advanced here apply in any gatekeeping regime in which liability is imposed on a provider of goods or services in order to improve the behavior of the customer. For general discussion, see Kraakman, supra note 33, at 74-81 (discussing overdeterrence problems). For recent analyses of lawyers' obligations applying a gatekeeper analysis, see, for example, Jackson, supra note 53; David B. Wilkins, Who Should Regulate Lawyers?, 105 HARV. L. REV. 801 (1992). 
desirability of advice that assists the client in lowering expected sanctions, the lawyer will also want to assess issues of access to information and the motives and legal competence of possible observers. ${ }^{154}$ Collecting and evaluating this information is costly, and those costs will inevitably increase legal fees. Increased fees, in turn, reduce the advice bought and given, including much desirable legal advice.

More important, even a lawyer who diligently endeavored to provide only desirable advice would face substantial expected legal sanctions under a general standard. This would be especially true if the standard embodies a nebulous standard of social desirability - like promoting "justice"155 or avoiding "immoral" projects"156 - for then the lawyer must guess which standard of social desirability the tribunal will adopt in her case.

But even if the general standard stipulated some concrete measure of social desirability - say Posnerian economic efficiency, Rawlsian distributive justice, or the substantive norms underlying current law - the risk of legal sanctions would remain. Lawyers' judgments about whether their advice meets the stipulated standard of desirability will often be uncertain or prove inaccurate. Lawyers will have to make predictions of how the advice will affect their client's behavior and how a tribunal will judge the effects of their advice. The latter will be particularly difficult because ex post adjudication of the desirability of advice will be hard to predict and often inaccurate. The tribunal will likely have incomplete information because often there will be no physical evidence about, or disinterested witnesses to, the advice given. Moreover, a general standard will exacerbate the risk of inaccuracy because such a standard is more manipulable and heavily dependent in application on contextual elements of the situation that may be poorly captured in an ex post inquiry. Thus, even well-motivated and competent tribunals will often have a hard time reaching an accurate determination whether to sanction. ${ }^{157}$ Such uncertainty will often lead lawyers to forgo desirable advice for fear of legal sanctions.

154. William Simon, for example, anticipates that litigation counsel would ordinarily conduct such an assessment of the competence of the opponent and the tribunal before giving litigation advice. See Simon, supra note 1, at 1100 (suggesting that the lawyer has an obligation to assess the risk of institutional failure). Similarly, David Wilkins argues that Kaye, Scholer had an obligation to assess whether the effectiveness of its opponent, the Federal Home Loan Bank Board, had been impaired by "political pressures," and, if it detected such an impairment, to moderate its advocacy accordingly. Wilkins, supra note 8, at 1194-95.

155. Id. at 1090.

156. LUBAN, supra note 9, at 160-61.

157. Cf. Kraakman, supra note 33, at 73 ("Equally important, both courts and gatekeepers are likely to err in rough proportion to the complexity of misconduct or the ambiguity of the law."). 
Infrequent detection of prohibited advice may worsen the problem of overdeterrence. Infrequent detection is likely for several reasons. Accurate information requires full monitoring of lawyers' activities, including their interactions with clients, a prohibitively costly enterprise. ${ }^{158}$ Even if there were no formal rules requiring attorneys to keep silent about their clients' affairs, ${ }^{159}$ few cases of wrongdoing would be reported. If the lawyer has provided advice that prevents desirable conduct, the matter will often never come to light. If the lawyer has given advice that encourages undesirable conduct, neither lawyer nor client have any incentive to say anything unless the client actually engages in the harmful activity, is caught, and concludes that the advantages of attacking the lawyer exceed the advantages of making common cause with him. ${ }^{160}$ Even if this occurs, the lawyer's greater legal sophistication may often allow him to obscure what actually took place or to dominate a "swearing match" with the client.

Infrequent detection and inaccurate adjudication combine to create a difficult problem of sanctioning policy. Infrequent detection might seem to call for severe, perhaps even career-threatening, sanctions in cases where improper advice is detected. ${ }^{161}$ But, given the inaccuracy of adjudication under a general standard of social desirability, this approach will potentially subject a great deal of desirable advice to very severe sanctions.

The problem of overdeterrence under a general standard would operate across the full spectrum of advice, but its extent would vary depending on the kinds of lawyers, clients, and legal issues involved.

158. Obviously monitoring would be very costly simply as a matter of information gathering. The cost would be greater, of course, to the extent that monitoring also violated basic privacy values or deterred desirable advice. See supra note 21 and accompanying text. Full analysis of confidentiality rules is beyond the scope of our present discussion except to note that, under an open-textured standard, even full information about the interaction between lawyer and client would not eliminate the risk of mistaken sanctioning. For an analysis of confidentiality in litigation, see Bundy \& Elhauge, supra note 33, at 401-13.

159. See, e.g., Model Rules of Professional Conduct Rule 1.6 (1992) (forbidding disclosure of information "relating to the representation").

160. See Wilkins, supra note 153, at 834 (noting that the client seldom has incentive to turn in its "partner in crime"). Professor Wilkins' analysis of the question of who should exercise regulatory authority over lawyers echoes many of the themes explored here, particularly the different effects of lawyer regulation designed to curb excesses of lawyer zeal on different classes of clients. But his analysis does not focus on the issue as it arises in the context of formulating rules for the provision of legal advice because he assumes that different regulatory authorities will generally enforce the same set of rules. His analysis of the Kaye, Scholer matter, however, expressly considers the relevance of client type to the content of professional regulation. Wilkins, supra note 8, at 1206-09 (discussing how sophisticated clients can avoid overdeterrence).

161. For example, the remedy obtained in the Kaye, Scholer litigation barred two lawyers from the firm from representing regulated savings and loan clients in perpetuity. In re Fishbein, OTS AP-92-25 (Department of Treasury 1992) (order of prohibition and disbarment); In re Katzman, OTS AP-92-26 (Department of Treasury 1992) (same). 
Where a significant possibility exists that lawyers would mistakenly be assessed severe sanctions, lawyers who are risk averse or who have high risk-bearing costs would be more severely deterred from giving desirable advice. ${ }^{162}$

Some clients would also experience greater overdeterrence than others. Because increased compliance costs would make legal advice more expensive, clients with less wealth would have to forgo more desirable advice, and thus suffer greater overdeterrence, than wealthier clients. Clients unfamiliar to the lawyer are also likely to experience greater overdeterrence. When a client is unfamiliar, the lawyer knows less about what the client knows, how advice will influence the client's conduct, and the benefits to the client of engaging in the conduct. Unfamiliar clients therefore increase both the costs of complying with a general standard and the residual risk of being held liable even if one has complied. Overdeterrence should therefore be less severe for clients whom the lawyer has represented before, whom he knows from other social settings, or with whom he shares common traits or experiences. Overdeterrence will be more severe for clients who are onetime users of the legal system or are of a different race or socioeconomic background than the lawyer. ${ }^{163}$

One can also expect greater overdeterrence for clients who cannot effectively bargain for advice, whether due to distress (so that they lack the time and energy to shop for a lawyer), inexperience, or inability to offer repeat business. Such clients are less likely to recognize when they have been denied desirable advice and less able to make credible threats to take present or future business elsewhere. ${ }^{164}$ Overdeterrence may be particularly severe if, as seems plausible, there is a significant overlap between the universes of risk-averse lawyers, less wealthy clients, unfamiliar clients, and clients who cannot bargain for advice.

Overdeterrence is also more likely for certain types of legal issues. Its impact is likely to be more severe for small-stakes claims or issues, where increased compliance costs often dwarf the value of the advice. Overdeterrence will also be greater when the lawfulness of the client's

162. See Jackson, supra note 53 , at $1065 \&$ n.67 (discussing risk aversion among lawyers).

163. See id. at 1056 \& n.139 (risky savings and loans denied advice); Kraakman, supra note 33 , at 77 (rejection of risky clients).

164. One should not think of this as simply a problem of agency costs that conflict of interest rules can control. Recall that the decision to refuse a client or to withdraw from representation on moral grounds is essentially discretionary. Overdeterrence may therefore be reflected not primarily in failures to provide advice within a lawyer-client relationship, but rather in failures to commence or continue relationships. Moreover, within relationships between lawyers and oneshot clients, conflict of interest rules are significantly underenforced, largely on account of low rates of client detection. Wilkins, supra note 153 , at 822-30. 
conduct is uncertain. Under standards framed in terms of justice or social desirability, overdeterrence will also increase when the lawyer's professional competence does not enable him to determine with confidence whether the client's conduct will be socially desirable. Classically the lawyer's legal training and experience equip her to determine whether particular conduct is sanctionable and, sometimes, the level of expected sanctions. When sanctionability or the level of expected sanctions are weak proxies for social desirability, that training is unlikely to provide her with any special advantage in evaluating the conduct. In general, we might expect a weak correlation between sanctionability and social desirability when the applicable rules do not seek to prohibit conduct outright, but rather to price conduct by making the actor internalize its social costs. ${ }^{165}$ The desirability of such conduct turns not on whether the conduct is sanctionable or on the level of expected sanctions, but on whether its private and public benefits exceed its private and public costs, an issue on which the lawyer may well doubt her competence.

The potential differential impact in deterring advice also has disturbing implications for the provision of advice with undesirable behavioral consequences that is nonetheless justified on fairness grounds. ${ }^{166}$ Consider first the class of cases in which fairness calls for advice notwithstanding the risk that it will deter desirable conduct. When the law is contested, or the legal rules price conduct rather than prohibit it, actors will often face severe expected sanctions despite their correct - or at least reasonable - belief that their proposed conduct is socially desirable. As we have seen, however, those conditions also increase the likelihood of overdeterring advice under a general standard. Such a standard therefore increases the risk that actors will be unfairly sanctioned for desirable conduct. That risk will be still more grave for clients with limited resources, unfamiliar clients, and clients who cannot effectively bargain for advice. The greater overdeterrence of advice for those classes of clients may also create troubling problems under the fair fight principle when such clients oppose parties who do not suffer from those disadvantages. ${ }^{167}$

165. This distinction was apparently introduced to the law-and-economics literature by Robert Cooter. See Robert Cooter, Prices and Sanctions, 84 Colum. L. Rev. 1523 (1984). The distinction has recently been strongly pressed in the recent work of John Coffee. See John C. Coffee, Does "Unlawful" Mean "Criminal"?: Reflections on the Disappearing Tort/Crime Distinction in American Law, 71 B.U. L. REV. 193, 225.28 (1991) [hereinafter Coffee, Reflections]; John C. Coffee, Jr., Paradigms Lost: The Blurring of the Criminal and Civil Law Models - And What Can Be Done About It, 101 YALE L.J. 1875, 1876 \& n.6 (1992) (describing the distinction) [hereinafter Coffee, Paradigms Lost].

166. See supra section III.A.

167. This problem arguably has arisen under Federal Rule of Civil Procedure 11, where 
Accordingly, proposals for a general standard condemning undesirable advice should have more appeal when clients are repeat players who are familiar to their lawyers and, hence, run less risk of being denied desirable advice on account of overdeterrence. Indeed, although proponents of more general standards have not explicitly recognized this overdeterrence problem, their actual positions are consistent with our conclusions about the distribution of overdeterrence. Thus, critics of the present regime of professional ethics strongly emphasize its overinclusiveness as applied to sophisticated business entities, ${ }^{168}$ for whom overdeterrence is less problematic. And proponents of more general standards often express reluctance to extend their approach to cases involving unfamiliar or unsophisticated clients, ${ }^{169}$ for whom we would predict greater overdeterrence. In short, the viability (if any) of a general standard policing undesirable advice may depend on limiting its application to settings in which all or most clients are familiar, sophisticated repeat players with relatively large economic stakes in the issues. Proceedings before federal regulatory agencies like the SEC and OTS, where such standards have been proposed, might arguably be such settings. ${ }^{170}$

Specialized regulatory settings may also influence other undesirable effects of a general standard. First, if lawyers and regulators are both genuinely expert in the underlying subject matter, that expertise may reduce both the degree of uncertainty about how general standards should be interpreted and applied and the residual risk of error in doing so. ${ }^{171}$ Second, if such settings involve repeated interactions among a well-defined community of lawyers and regulators, those interactions may over time generate relatively firm understandings about the meaning and application of such standards. Third, such forums may sometimes permit low cost increases in the rate of enforcement,

evidence suggests that sanctions directed at lawyers and litigants have deterred individual plaintiffs - and particularly civil rights plaintiffs - more severely than organizational defendants. Lawrence Marshall et al., The Use and Impact of Rule 11, 86 Nw. U. L. REV. 943, 970-75 (1992).

168. See Rhode, supra note 127, at 607-08; William H. Simon, The Ideology of Advocacy: Procedural Justice and Professional Ethics, 1978 WIs. L. REV. 29, 109.

169. See LuBAN, supra note 9, at 66 (suggesting that traditional notions of zealous advocacy should apply for defendants in criminal cases and for parties in civil cases when the client is much less powerful than his opponent); Simon, supra note 1, at 1084 (limiting his approach to civil practice and excluding criminal cases).

170. See Wilkins, supra note 8, at 1207 (arguing that savings and loan institutions are "sophisticated repeat users of legal services" who can protect themselves against costs associated with defensive lawyering).

171. Cf. Kraakman, supra note 33, at 83 (arguing that the expertise of the securities bar and underwriting community has helped to "focus" due diligence obligations under the federal securities laws). 
which in turn may make it possible to maintain deterrence while reducing actual sanctions toward the level of social harm, rather than some multiple thereof. This should reduce overdeterrence due to risk aversion or high risk-bearing costs. ${ }^{172}$

\section{An Ethical Prohibition on Undesirable Advice}

In lieu of a general legal prohibition on undesirable advice, some critics suggest propounding a comparable rule as an ethical norm, drilled or socialized into lawyers during law school or by professional associations and interactions. ${ }^{173}$ Generally this is presented as a more modest, and easier to justify, proposal than the legal reform just considered. Again, we put aside questions about practicality, such as whether such socialization could be sufficiently effective to change legal practice. Rather, we focus on the question whether, if effective, such an ethical norm would have desirable consequences overall, or at least more desirable consequences than a legally imposed standard.

Such proposals for a new ethical or professional norm of avoiding undesirable advice must contemplate that socialization will overcome the lure of legal fees in one of two ways. First, social sanctions, such as professional disparagement, may coerce attorneys into complying with the norm despite financial incentives to the contrary. Second, legal education or professional training may instill the norm so deeply into lawyers that they will comply automatically despite contrary financial incentives ${ }^{174}$ or will experience sufficient internal rewards from compliance (or guilt from violations) to overcome those financial incentives. ${ }^{175}$ Such ethical norms can be effective in accomplishing their stated aim - namely denying advice when it would lead to undesirable consequences - only if lawyers complying with the ethical norm have sufficient market power that clients seeking undesirable advice cannot simply turn to alternative lawyers with lower or different ethical standards.

With regard to social sanctions, our analysis parallels that in the last section. Like legal sanctions for undesirable advice, social standards will impose higher compliance costs, with disproportionate ef-

172. Cf. Jackson, supra note 53, at 1063-67 (discussing the relation between enforcement rates, sanction levels, and overdeterrence).

173. See, e.g., LUBAN, supra note 9, at 158-59; Simon, supra note 1, at 1084 (presenting as an alternative thesis that his proposed duty to "do justice" could be incorporated into individual ethical judgment rather than professional rules).

174. Cf. Kornhauser, supra note 39.

175. See Ronald S. Gilson, The Devolution of the Legal Profession: A Demand Side Perspective, $49 \mathrm{MD}$. L. REv. 869, 886-89 (1990) (arguing and collecting sources to support point that lawyers can be motivated or socialized to choose virtue over income). 
fects on less wealthy, less familiar, and less sophisticated clients. Also like legal sanctions, social sanctions will be uncertain and often imposed inaccurately. Indeed, social sanctions probably will be even more nebulous than general legal standards, in part because social judgments express no uniform rationale or binding precedent. Moreover, because social condemnation will often rest on superficial judgments and casual observation, the imposition of social sanctions is more likely to be inaccurate even if the social norm were perfectly specified. A familiar example is the fear that individuals who have been judged guilty by the media would find it difficult to secure counsel. If the fear of social sanctions can overcome the desire for income sufficiently to deter undesirable advice, that same fear of social sanctions would also deter lawyers from giving many forms of advice that would in fact be desirable.

Distributional problems will also accompany social sanctions applied by members of the profession. Not only will the unfamiliar, one-shot client seem more risky to the advising lawyer (and more costly to investigate), but those same characteristics are also likely to make the client unfamiliar to the members of the profession generally, thus decreasing the accuracy of the social sanctioning process. One might thus expect professional social sanctions disproportionately to overdeter advice to clients who come from a different socioeconomic background than their lawyers or who have one-shot or nonroutine claims. ${ }^{176}$

Social sanctions, however, do have at least one potential advantage over legally enforced sanctions: social interactions may be more likely than legal rules to detect and punish the giving of undesirable advice. In practice settings where lawyers interact frequently and reputational networks are strong, a lawyer may fear the condemnation of legal peers who can observe his behavior far more than the unlikely prospect of a disciplinary hearing. This greater ease of detection can make social sanctions more effective, even though far less severe when imposed, than legal sanctions. We thus do not argue that social sanctions are in any sense an inferior means of regulating undesirable forms of advice - just that they raise problems of overdeterrence similar to those raised by legal sanctions.

Internalized professional norms present a more mixed picture. Under this approach, the well-socialized lawyer will be self-monitoring

176. Indeed, some have criticized professional rules regulating legal advertising or soliciting clients, acquiring an interest in litigation, and fee divisions among lawyers as intended to deter selectively advice that increases the likelihood of claims by personal injury, consumer, or civil rights plaintiffs. See supra note 149. Such clients tend to be one-shot and often unfamiliar. 
and self-sanctioning, which reduces overdeterrence problems stemming from low detection rates and inaccurate sanctioning. Compliance costs should, however, continue to overdeter desirable advice, both generally and with respect to less wealthy, less familiar, and less experienced clients.

The open-textured nature of the standard, however, may mean that underdeterrence is not effectively corrected for clients who can shop for advice. To understand this observation, we must focus on what sort of norm, precisely, would be instilled. Suppose, for example, the norm is quite general and standardlike, requiring that each lawyer balance his client's interests against the interests of others or achieve the most just result in each case. ${ }^{177}$ Even well-socialized, conscientious lawyers applying such an open-ended norm will have a high error rate around the mean of social desirability. Accordingly, clients who can shop for advice will often obtain the advice they want by picking another lawyer or law firm when the first denies them advice. Moreover, to the extent such a standard invites lawyers to make their own moral judgments without reference to external standards of social desirability, different lawyers attempting to comply with the standard will (accurately!) reach sharply different conclusions, thus increasing sophisticated clients' ability to shop for the advice they want. The de facto stándard is, in short, likely to vary too much to be effective. Moreover, the inevitable tendency for self-interest to cloud factual and moral judgment will likely induce lawyers to underestimate the undesirability of advice, particularly as they see business migrate to those with laxer ethical standards.

Effective internalized ethical norms, then, must have sufficiently uniform content and application that clients lack ready alternatives. Since internal moral adjudication is private and decentralized, such uniformity can only be achieved if the instilled norms are rulelike, having broad, relatively precise application. Such rulelike internalized norms might resist the race to the ethical bottom. But, because they must be framed broadly, they raise inevitable problems of over- and underinclusion, and thus over- and underdeterrence, because they would not allow for contextual moral judgment.

As a more modest strategy a law firm might endeavor to exploit its own market power to cease providing certain clients with undesirable advice under an ethical norm particular to that firm. Law firms are normally too small to have market power in any general legal market. But, as Ronald Gilson has argued, often law firms do have market

177. See generally Simon, supra note 1 (proposing that lawyers act to promote justice.). 
power vis-à-vis certain clients because those clients have made relationship-specific investments in that firm. ${ }^{178}$ Such relationship-specific investments will make it costly for long-term clients to switch firms and thus gives firms some marginal market power to withhold desirable advice without losing their clients.

But a strategy based on single-firm market power faces four severe problems. First, in the long run a firm that pursues such a strategy will have difficulty acquiring new clients and will tend to lose business to other expanding firms. Second, as Gilson himself has noted, the increasing legal sophistication of long-term business clients, in part because of the expanding role of general counsel, has given clients greater ability to shop effectively, reducing the availability of this strategy. ${ }^{179}$ Third, because the strategy depends on repeat players, it is not feasible in markets dominated by one-shot clients. Finally, unless the firm can afford to lose the business of all clients against whom it lacks market power (new or sophisticated or one-shot clients), successfully pursuing this strategy would require distinguishing between these clients subject to the firm's market power (locked-in, unsophisticated, repeat playing clients) and those who are not, and then applying different ethical norms to each set of clients. ${ }^{180}$ Both distinguishing clients and especially applying dichotomous ethical norms are likely to prove difficult in practice. They may also give rise to new ethical problems stemming from the perceived need to prevent clients from learning of the alternate ethical standard. ${ }^{181}$

At the same time that it seems unlikely to deter advice to clients who can shop, a fully effective, open-textured ethical standard poses new risks of reducing desirable advice to unsophisticated or one-shot clients. The risks arise from the interaction of any ethical norm with the law of legal malpractice, which poses an interesting dilemma. ${ }^{182}$ Suppose, first, that compliance with a proposed ethical standard would not be a defense to a client's malpractice claim that she was denied legal advice. Such a rule would render the ethical standard all but a dead letter. Lawyers who otherwise would deny lawful advice to clients on ethical grounds will not persist when threatened with malpractice liability.

178. See Gilson, supra note 175 , at $889-98$.

179. See id. at 900-03.

180. Cf. 10 Phillip areeda et al., ANtitrust Law f 1740 (forthcoming 1994).

181. Cf. Mark Osiel, Lawyers as Monopolists, Aristocrats, and Entrepreneurs, 103 HARv. L. REv. 2009, 2016-17 (1990) (suggesting that lawyers practicing under a general standard would have to deceive clients).

182. Much of the argument here also applies to the interaction of legal malpractice liability with a professional code that attempts to require lawyers to deny undesirable advice. 
Alternatively, suppose that complying with the proposed ethical norm would be a defense to a malpractice claim. In that event, the ethical norm could seriously undermine the standard of care in providing advice mandated by the law of legal malpractice. The lawyer who failed to provide advice out of sloppiness could simply attribute the failure to misgivings about whether the advice would lead to socially undesirable consequences. Of course a tribunal might reject the lawyer's judgment as unreasonable, but then judges and juries in malpractice cases, rather than socialization and internal sanctioning mechanisms, would establish the effective standard of practice, reintroducing all the problems of over-and underdeterrence that attend ex post adjudication of a legal prohibition on undesirable advice. ${ }^{183}$

Undermining the effective legal standard of care under malpractice law will have a different effect on different clients. For the sophisticated, repeat-playing client, one doubts that the legal standard of care has much impact at all. Lawyers' interest in preserving their reputation for good legal work should provide a sufficient incentive for them to take care. But shoddy work done for unsophisticated, one-shot clients by definition has no impact on future business with the client and will likely have little impact on the lawyer's general reputation either. Again, the distributional impact of the advice forgone - through increased cost, deterrence, or sloppiness - seems likely to impact unsophisticated or one-shot clients disproportionately. ${ }^{184}$

\section{The Triggering Function of the Traditional Crime-Fraud Line}

The disadvantages of a general legal or ethical standard seem to us to provide ample ground for a rule of bright-line legality for substantial categories of advice, at least for unfamiliar or one-shot clients. The question remains why traditional professional norms draw the rule of bright-line legality just shy of known fraud or crime, rather

183. This will be largely true even if the tribunals apply the subjective test, limiting their inquiry to whether the lawyer in fact thought the advice was undesirable. Absent a smoking gun - such as the lawyer's own admission - subjective intents must be determined by inferences that are inevitably based on some implicit understanding of what a reasonable person would have thought under the circumstances.

184. Very recent work by Luban and Simon shows an emerging awareness of the potential effects of a discretionary ethical standard on the quality of representation provided to unsophisticated, powerless parties. It also documents a divergence of their views concerning the severity of such effects. Compare David Luban, Are Criminal Defenders Different?, 91 Mich. L. REv. 1729, 1757-59 (1993) (arguing that a discretionary ethical standard for "aggressive advocacy" in criminal cases should be rejected because it would encourage incompetent practice) with William $\mathrm{H}$. Simon, Reply: Further Reflections on Libertarian Criminal Defense, 91 MICH. L. REV. 1767, 1769-71 (1993) (discounting that risk). In this exchange, as in earlier work, neither author devotes any attention to the problems of overdeterrence that might result if their proposed standards were embodied in legal norms enforced through coercive sanctions. 
than at some other point. In our view, that choice appears most plausible on the assumption that the crime-fraud line accurately distinguishes those laws that, because they are narrowly drawn around the most egregious conduct, that are relatively less overinclusive and relatively more worrisome in terms of underdeterrence. ${ }^{185}$

If crimes and frauds substantially exhaust the categories of laws that are narrowly drawn around highly undesirable behavior, then seeking to prohibit advice that facilitates undesirable conduct outside those categories runs a severe risk of overdeterring advice justifiable on behavioral or fairness grounds. For it would follow that, outside that category, overinclusion and overdeterrence present greater problems.

The assumption that crime and fraud laws are relatively less overinclusive also helps to justify the more complex and open-textured rule governing the provision of advice about known crimes or frauds. Recall that, under this rule, advice that the conduct is unlawful is clearly permitted, but other types of advice are shadowed by uncertainty concerning the boundary between permitted analysis and prohibited assistance. ${ }^{186}$ If contemplated criminal or fraudulent conduct is almost always undesirable, advice that it is sanctionable will seldom have undesirable behavioral effects. After all, such advice should stop normally law-abiding clients in their tracks, regardless of the level of expected sanctions. Even if clients are not law abiding, learning that their proposed conduct is criminal or fraudulent will never increase the likelihood that they will engage in it. The severity of the criminal sanction, moreover, provides compelling fairness reasons for providing such advice. Conversely if crimes and frauds (and conduct bordering on them) are almost always undesirable, there is no social value in and rarely any fairness argument for - advice that allows parties to lower expected sanctions. A complete prohibition seems appropriate.

On the assumption that crime and fraud laws exhibit low overinclusion, the indeterminate status of intermediate kinds of advice, such as advice about the level of expected sanctions, also seems appropriate. Granted, such advice can be socially desirable when the client underestimates expected sanctions. But, in most other respects, it appears uniquely dangerous. A client who expresses interest in the level of expected sanctions for conduct he already knows to be criminal or

185. See Parker, supra note 32, at 759-60 nn.51-56 (collecting sources holding the view that criminal behavior is particularly valueless with little surrounding productive behavior to be overdeterred). Many believe that this is how the criminal law should operate. Coffee, Paradigms Lost, supra note 165, at 1876 (arguing that the criminal law should be limited to prohibiting conduct that society believes "lacks any social utility"). Whether it now does so in fact is more doubtful. See $i d$. at 1878-82.

186. See supra notes $131-36$ and accompanying text. 
fraudulent is unlikely to be law abiding. Thus, if the client overestimates expected sanctions, advice will strongly increase the likelihood of undesirable conduct. And, because advice about the scope of sanctions should provide full notice that the conduct is wrongful, there is no independent fairness justification for advice about the level of sanctions.

It may therefore be appropriate to regulate advice about expected sanctions for known crime or fraud under a probabilistic standard, permitting such advice when it corrects underestimations of expected sanctions, but forbidding it when it corrects overestimations. The risk that such a standard will deter desirable advice is lower because, given the situation, less advice is desirable. Moreover, the risk of selectively overdeterring desirable advice to unfamiliar or unsophisticated clients is less, both because a client's continued interest in the level of expected sanctions provides important confirmation of her character and because determining the social desirability of the client's conduct no longer depends on a costly and potentially erroneous inquiry into the level of benefit to her.

On this account, the structure of the rules on advice adopts what one of us has elsewhere described as a "triggering" approach. ${ }^{187}$ A triggering approach is often a useful regulatory strategy when there are two alternative legal doctrines: one that exhibits less underdeterrence at the expense of greater overdeterrence, and another that exhibits less overdeterrence at the expense of greater underdeterrence. The former doctrine would be better if underdeterrence problems predominate; the latter would be better if overdeterrence problems predominate. Rather than simply choosing one of the doctrines to apply in all cases, however, sometimes the law can apply each doctrine selectively by employing a metarule to segregate the general class of cases into one class in which underdeterrence problems dominate and another class in which overdeterrence problems dominate. That metarule would then trigger the application of the first doctrine to the first class of cases and the second doctrine to the second class. Each doctrine would accordingly be focused on the sorts of cases in which its mix of under- and overdeterrence is most appropriate, which may optimize overall over- and underdeterrence better than any single doctrine could.

Here, the metarule rests on the presence or absence of known criminal or fraudulent activity. Where there is known criminal or fraudu-

187. Einer Elhauge, The Triggering Function of Sale of Control Doctrine, 59 U. CHI. L. REv. 1465 (1992). 
lent activity, this metarule "triggers" what is in effect a general standard to police undesirable advice about the level of expected sanctions. Although such a general standard has the serious overdeterrence problems we raised above, it does reduce underdeterrence of undesirable advice. It is thus particularly well suited for a class of cases in which underdeterrence problems predominate, which by hypothesis are the cases triggered by the crime-fraud rule. Outside of the crime-fraud area, overdeterrence concerns become far more serious, and underdeterrence concerns less serious. There, the traditional permission of advice, which reduces overdeterrence of desirable advice at the expense of underdeterring undesirable advice, may be more appropriate. Arguably, this triggering approach can minimize the overall harm from the overdeterrence of desirable advice and underdeterrence of undesirable advice more effectively than applying in all cases either a rule of permission or a general standard prohibiting undesirable advice.

The ultimate plausibility and wisdom of this account as a guide to policymaking depends critically on the underlying assumptions. If the categories of crime and fraud exclude many laws that have little overinclusion or overdeterrence, the current bright-line rules of legality may significantly underdeter undesirable advice. Critics of the traditional rules clearly believe this is a significant problem. ${ }^{188}$

Cutting the other way, however, is the present expansion of criminal law to cover less egregious forms of misconduct and to "price" conduct that has substantial social benefits. ${ }^{189}$ This expansion suggests that, in many cases, advice that corrects overestimations of criminal sanctions, even for known criminal conduct, may have substantial social value because the conduct is itself desirable. The social value of the advice is likely to be even higher for conduct bordering on criminal

188. Thus, in discussing corporate counsel's responsibilities in the Ford Pinto case, David Luban argues that "it can make no difference whether or not Ford's actions in the Pinto situation violated a criminal statute: it is the actions themselves rather than their legal classification that give rise to the need for whistleblowing." See LUBAN, supra note 9, at 215; see also Simon, supra note 1, at 1127 (arguing in support of his "discretionary" approach that categorical norms "tend to be both overinclusive and underinclusive relative to their purposes").

Not surprisingly, defenders of the traditional approach point to cases in which non-criminal regulation prohibits desirable conduct. See, e.g., John K. Villa, Emerging Theories of Liability for Lending Counsel, in THE ATTORNEY CLIENT RELATIONSHIP, supra note 55, at 93, 153.55 (describing cases in which conduct violating regulations governing loan underwriting may be socially desirable).

189. See Coffee, Paradigms Lost, supra note 165 , at $1878-82$ (discussing criminalization of common law of breach of fiduciary duty, growth of vicarious liability, and proliferation of federal regulations with potential criminal penalties); Coffee, Reflections, supra note 165, at 208-09 (describing criminalization of breach of contract); id. at 228-29 ("The negligent [criminal] defendant is frequently engaged in activities that have social utility and, indeed, is the same person with whom the law of torts regularly deals."). 
behavior that might be mistaken for it. The expansion of criminal law also suggests that fairness considerations may increasingly justify advice that corrects underestimations of expected sanctions for such conduct because actors may correctly believe that such conduct is socially desirable. In either instance, the standard governing the provision of advice about criminal conduct may increasingly overdeter desirable advice. ${ }^{190}$ Critics of current professional rules have neglected this risk.

\section{KNOWLEdge About SANCtions ANd Acoustic SEPARATION}

Those familiar with Meir Dan-Cohen's analysis of acoustic separation may find it odd that we bring it up in this article. After all, DanCohen's work is a piece of jurisprudence, not rational actor modeling. But, reconsidered in light of the preceding analysis, his acoustic separation argument in fact can be mined for several insights into general questions about the desirability of encouraging or discouraging the dissemination of knowledge about legal sanctions.

\section{A. Dan-Cohen's Analysis}

Dan-Cohen begins with a well-established jurisprudential distinction: that between conduct rules and decision rules. ${ }^{191}$ Conduct rules are legal rules directed at the general public and intended to guide its conduct. Decision rules are legal rules directed at government officials and intended to guide their adjudication of the public's conduct.

One might think this distinction has little practical significance. Conduct rules that define illegal conduct and its penalty would necessarily seem to imply a parallel decision rule: that officials should apply that conduct rule and impose the penalty it provides on violations thereof. Conversely, a decision rule that officials should condemn and punish certain behavior appears to imply a parallel conduct rule: that individuals should avoid such behavior or suffer the penalty the decision rule authorizes. But, Dan-Cohen argues, this parallel is not compelled logically, empirically, or normatively.

Logically, the judge who applies, for example, the rule forbidding theft is not bound by the conduct rule that prohibits theft; failing to impose the proper penalty on theft does not itself constitute theft. 192 The judge is bound rather by a decision rule for imposing punishment,

190. Indeed, if the phenomenon of criminal sanctions for conduct with some social value were to become sufficiently widespread, even a prohibition on assisting such conduct might sweep too broadly.

191. Dan-Cohen, supra note 14 , at 625-30.

192. Id. at 628. 
one element of which may be the conduct rule defining theft. Imagine, then, that adjudicators and the general public are separated into different acoustically sealed chambers. In that event the legal regime could communicate decision rules to adjudicators without those rules being overheard (and turned into conduct rules) by the general public. ${ }^{193}$ Decision rules need not logically be the same as conduct rules.

Empirically, of course, conditions of complete acoustic separation hardly ever exist. The general public does hear about adjudicative decisions. But, Dan-Cohen argues, often conditions of partial acoustic separation do exist. ${ }^{194}$ The general public may have difficulty grasping, or find it too costly to learn, the complex decision rules that are directed at adjudicators and may thus rely on the more simple conduct rules directed at the general public. Moreover, sometimes the legal regime can, perhaps not intentionally, employ a strategy of selective transmission, which furthers or protects the acoustic separation between conduct rules and decision rules. These strategies include misleading maxims, legal vagueness and complexity, giving technical legal meanings to ordinary words, and denying defenses to those likely to have or obtain legal sophistication before acting. ${ }^{195}$

One example of this selective transmission appeared in the introduction to this article. "Ignorance of the law is no excuse" is the simple but misleading maxim of conduct disseminated to the general public; the actual decision rule involves a complex set of conflicting factors weighing for and against allowing the defense. ${ }^{196}$ The very simplicity of the maxim, compared to the complexity of the factors, makes it likely that partial acoustic separation can exist between the conduct rule reflected in the maxim and the decision rule reflected in the complex of factors.

Another example, Dan-Cohen argues, lies in the defenses of duress or necessity. ${ }^{197}$ These defenses are so vague and complex that the average citizen cannot understand or rely on them. Thus the general public tends to be guided by a conduct rule that corresponds to the legal violations shorn of these defenses, while the defenses do form

193. Id. at 630.

194. Id. at 634.

195. Id. at $639-40,648,652$. Another strategy might be to prevent lawyers from learning the information in the first place. In the past, for example, the Internal Revenue Service did not make private revenue rulings or internal auditing standards publicly available. And, arguably the published antitrust merger guidelines were stricter than the actual practice of the Department of Justice's Antitrust Division during the Reagan Administration. Of course, such strategies put a premium on hiring ex-IRS agents, or ex-lawyers from the Antitrust Division, as accountants or lawyers. We are indebted to Walter Blum for this point.

196. Id. at 645-48.

197. Id. at 639-45. 
part of the decision rule used by courts. Moreover, courts tend to deny the defenses to individuals who have special legal sophistication or are in circumstances that lend themselves to prolonged deliberation over, and perhaps obtaining advice concerning, the legal consequences of contemplated conduct. This occurs, Dan-Cohen argues, because there is little acoustic separation in these cases and thus no way to effectively keep the conduct and decision rules distinct.

Normatively, is such selective transmission desirable? Not always, Dan-Cohen concedes, but the conclusion that decision rules and conduct rules should be identical is not always normatively compelled either. Instead, the matter must be decided in each area in accord with the policies and values that seem relevant. ${ }^{198}$ Consider, for example, selective transmission regarding the defenses of duress and necessity. Obscuring these defenses from conduct rules, Dan-Cohen argues, can have beneficial behavioral effects: it helps ensure that individuals commit legal violations only when they truly think the alternatives are worse than the legal penalties. ${ }^{199}$ But allowing these defenses in decision rules avoids the unfairness or harshness of punishing behavior that was compelled by circumstances beyond the actor's control. ${ }^{200}$ Without acoustic separation and selective transmission, the law must choose between good behavioral effects and fairness in adjudication. With them, the law can have both. Therefore, Dan-Cohen concludes, it is far from obvious that selective transmission is normatively undesirable. ${ }^{201}$

\section{B. Acoustic Separation in Our Model}

Dan-Cohen sums up his analysis as follows: "[W]e may expect the law to engage in selective transmission (1) under conditions of partial acoustic separation, and (2) in pursuit of policies that are best served by decision rules that differ from the corresponding conduct rules."202 We can use our framework to specify, generalize, and then extend these conclusions.

In all of Dan-Cohen's examples of partial acoustic separation, the conduct rules transmitted to the public exaggerate the scope of criminal conduct by omitting or obscuring defenses or limitations. We can thus rephrase his first condition more specifically as "(1) individuals overestimate the scope of conduct subject to criminal sanctions." Fur-

198. Id. at 629,634 .

199. Id. at 633,638 .

200. Id. at 633-34, 637 .

201. See generally id. at $665-77$ (assessing the legitimacy of selective transmission).

202. Id. at 636 . 
ther, in all the examples meeting his second condition, the decision rules are more lax than the conduct rules that would optimize behav. ior. We can thus rephrase this second condition more specifically as "(2) the scope of conduct subject to criminal sanctions is narrower than would, if known, optimize behavior."203 If these two conditions are met, then it may be desirable for society to promote good behavior by employing a strategy of selective transmission: that is, by diminishing the knowledge citizens possess about legal sanctions. Curbing legal advice, the strategy we have focused on until now, is one way of furthering this acoustic separation. But the other methods Dan-Cohen cites - such as vagueness, complexity, misleading maxims, and giving technical definitions to ordinary words - are other possibilities.

Our framework further suggests two immediate ways to generalize Dan-Cohen's claims. First, the conclusion applies to civil conduct as well as criminal. Second, the conclusion applies to overestimations of the level as well as scope of expected sanctions. Thus we may generalize as follows. If (1) persons overestimate expected sanctions (whether because they exaggerate the scope of criminal conduct or some other reason); and (2) the actual level of expected sanctions, if known, would offer less than optimal deterrence (whether because of the defenses and limitations contained in decision rules to pursue nondeterrence goals or some other reason), then a strategy of diminishing knowledge about legal sanctions (such as curbing legal advice) may be desirable to prevent the overestimations from being corrected. This generalization would suggest, for example, that, in addition to communicating simple harsh conduct rules and obscuring the substantive defenses, the law might (as long as acoustic separation exists) profitably pursue a strategy of selective transmission by threatening long prison terms for conduct even though the legal regime in fact ameliorates those sentences with a complex regime of judicial discretion and probationary releases.

We may further use our framework to specify the circumstances in which the behavioral consequences of such efforts to diminish knowledge about legal sanctions will in fact be desirable. ${ }^{204}$ Namely, when-

203. Dan-Cohen emphasizes that decision rules might be narrower than behaviorally optimal rules because of nonbehavioral goals such as fairness in adjudication or limiting the discretion of adjudicators. Id. at 633-34, 648, 650-51,661-64. While our model includes such nonbehavioral goals, we also recognize that decision rules may be narrower than behaviorally optimal for a host of other reasons as well. See supra section I.B.2.

204. Whether the resulting improvements in behavior will justify the use of selective transmission, in this or any other case, also depends on the fairness of allowing some actors to proceed in ignorance. See supra section III.A and infra text accompanying and following notes 207-09. 
ever condition (3) is met: "The socially desirable overestimations of sanctions for undesirable conduct outweigh (on whatever normative scale one wishes to apply) the socially undesirable overestimations of sanctions for desirable conduct."205 This condition might be met because potential undesirable actors make more errors or larger errors of overestimation than potential desirable actors. Or it might be met because the undesirable conduct encouraged by full advice tends to do more harm than the desirable conduct encouraged by advice does good.

Unless overestimations of sanctions for desirable and undesirable conduct systemically differ, this third condition should generally follow from the second condition that sanctions are lower than those that would optimize behavior if fully known. ${ }^{206}$ This is because, starting from such below optimal sanctions, an actual increase in expected sanctions for both undesirable and desirable conduct would, by definition, have behavioral effects that are, on balance, socially beneficial. A perceived increase in expected sanctions should have similar behavioral effects, as long as the overestimations exhibit no systemic divergence.

Our framework also suggests two extensions to Dan-Cohen's claims. First, the analysis applies to underestimations as well as overestimations. Thus, the behavioral consequences of a strategy of selective transmission (such as curbing legal advice) should be socially desirable if (1) persons underestimate expected sanctions, (2) the actual level of expected sanctions is excessively high, and (3) the underestimations for desirable conduct outweigh the underestimations for undesirable conduct. As in the last paragraph, the third condition should generally follow from the second.

For example, consider antitrust liability for joint ventures. Suppose that the level of expected sanctions for joint ventures is too high. Suppose, further, that businesses would be unaware of this potential liability without legal advice. They would, in other words, underestimate expected sanctions. Under these facts, a curb on antitrust advice might have desirable behavioral effects because such advice would discourage more desirable joint ventures than undesirable joint ventures.

The second extension involves cases in which over- and underestimations coexist and systemically diverge. Thus, the behavioral conse-

205. Dan-Cohen expressly recognizes this point with respect to overestimations of sanctions for criminal conduct. Dan-Cohen, supra note 14, at 638 \& n.29 ("The law's traditional resistance to allowing the defenses considered here in any but the most extreme cases may be understood to imply a belief that the benefits foregone because of overdeterrence in this area are more than offset by the danger of reduced obedience to the law that allowing these defenses would bring about.").

206. See supra section II.B. 
quences of selective transmission will be desirable if (1) persons overestimate expected sanctions for undesirable conduct and underestimate them for desirable conduct, and (2) the actual level of expected sanctions does not perfectly deter the conduct under consideration. Suppose, for example, unadvised individuals would both exaggerate the odds of being caught for insider trading and understate the odds of being held liable for trading when they had no inside information. In such a scenario, improving knowledge about legal sanctions can only worsen their behavior.

This last scenario, while perhaps rarer, provides when applicable the most sweeping justification for selective transmission because it should improve behavior even if fully disclosed sanctions would optimize behavior. Indeed, if selective transmission can be used in such a scenario, it will often be possible to improve behavior even further by adjusting sanctions away from the levels that would be optimal without selective transmission. Suppose, for example, that in the insider trading example the optimal sanction would, if known, equal the trader's stock profits given actual under- and oversanctioning. If with selective transmission insider traders would overestimate sanctions and innocent traders would underestimate them, then coupling selective transmission with an increase in actual sanctions to some multiple of trading profits may further optimize behavior. This is because the combination of selective transmission with such a sanction multiplier can reduce underdeterrence but still keep overdeterrence below the level that would be optimal if individuals accurately estimated sanctions.

All this might suggest that advice or knowledge about legal sanctions is far less justifiable than our prior argument would indicate. After all, in any of the above three scenarios, advice or knowledge about sanctions will have socially undesirable behavioral effects. This observation may tempt one to conclude that, at least for those areas of law where legal sanctions do not optimize behavior, we should discourage advice or knowledge about those legal sanctions.

This conclusion would, however, be premature. To begin, even when selective transmission strategies have clearly desirable behavioral effects, they may face strong fairness objections. From a fairness perspective, the least problematic scenario is that analyzed by DanCohen, in which behavioral improvements result from preserving overestimations of sanctions for undesirable conduct. ${ }^{207}$ As argued above, it is difficult to describe a persuasive principle of fairness which 
requires informing a potential bad actor that he can get away with misconduct. ${ }^{208}$ The fair notice claim to advice will be particularly weak if, as in Dan-Cohen's account, the use of selective transmission is limited to the criminal law. Hence, in the first scenario, actors would have a meritorious fairness claim to advice only in those relatively rare instances when the fair fight principle applies. ${ }^{209}$

However, the second and third scenarios raise more troubling fairness concerns. In the second scenario, selective transmission preserves a state in which underestimations of excessive sanctions for desirable conduct outweigh underestimations of sanctions for undesirable conduct. Because this strategy achieves its improvements in behavior by keeping desirable actors in ignorance of the legal risks that they run, it violates basic principles of fair notice. Some may regard this as a decisive objection to the use of this strategy.

In the third scenario, selective transmission achieves behavioral improvements both (1) by failing to correct underestimations for desirable conduct, and (2) by failing to correct overestimations for undesirable conduct. The latter aspect ordinarily poses no fairness concerns. The strength of the fairness objection to this strategy thus depends on the extent to which it achieves its behavioral effects by failing to correct underestimations of sanctions for desirable conduct.

More fundamentally, each of the three scenarios in which selective transmission can improve behavior has a mirror image in which advice or knowledge about sanctions would clearly improve behavior. In the mirror image of the first scenario, actors may underestimate insufficient sanctions instead of overestimating them. For example, they might think that criminal penalties are much lower than they actually are because of press coverage given to convicts released on parole.

In the mirror image of the second scenario, actors may overestimate excessive sanctions instead of underestimating them. They might, for example, think that the probability and magnitude of punitive damage awards in product liability cases are far higher than they actually are. This might result from extensive media coverage given those few cases in which punitive damages are assessed or from the media's tendency to give more coverage to high jury awards than to the judicial decisions reducing those awards.

Finally, in the mirror image of the third scenario, people may underestimate sanctions for undesirable conduct and overestimate sanctions for desirable conduct. They might, for example, think both that

208. See supra section III.A.

209. See supra text accompanying notes 128-30. 
the odds of being audited for an illegal deduction are lower than they are, and that the odds of being audited for a lawful deduction are higher than they are. In each of these alternative scenarios, selective transmission will likely be undesirable and legal advice desirable.

Absent evidence that the three troublesome scenarios occur more often than their opposites, advice and knowledge about sanctions must be regarded as ambiguous (rather than undesirable) in cases when sanctions, if known, would not optimize behavior. And, without such evidence, curbs on advice or other strategies of selective transmission must also be considered behaviorally ambiguous. In these behaviorally ambiguous scenarios, we think, fairness considerations will normally tip the balance in favor of full advice and knowledge.

The fact that the topic of legal knowledge concerns nonoptimal sanctions thus does not alone suffice to justify a curb on the dissemination of legal knowledge about sanctions. Sometimes even knowledge about nonoptimal sanctions can be desirable. Rather, efforts to diminish legal knowledge about nonoptimal sanctions, if justifiable at all, must rest on careful, contextual assessments of the actual over- and underestimations of the scope and level of expected sanctions that would, given the topic at hand, be made by parties lacking advice or knowledge about the applicable legal sanctions.

\section{CONCLUSION}

Ever since Adam and Eve, taking from the tree of knowledge has sometimes had undesirable consequences. Knowledge about legal sanctions is no exception. Advice or knowledge about legal sanctions does not always have desirable behavioral effects even when sanctions are set to optimize behavior. Instead, because of inevitable imprecisions in any sanctioning regime, advice or knowledge about optimal sanctions often will have undesirable effects.

However, as elsewhere in life, there is good reason to think that, despite some adverse consequences, more knowledge is on balance better. Unless the distribution of legal ignorance that would exist without advice is skewed, the overall behavioral consequences of advice or knowledge about sanctions will tend to be socially desirable if society has set sanctions to optimize behavior. Furthermore, where sanctions are set to optimize nonbehavioral measures of social welfare, advice and knowledge about sanctions will have ambiguous behavioral consequences, but may be justifiable on fairness grounds.

Under our analysis, the desirability of legal counseling and litigation advice do not categorically differ. Both are prone to the same mixed effects, and both should on balance be desirable if the applicable 
sanctions have been set to optimize behavior. Absent better empirical evidence, we have no reason to conclude that the sanctions for primary conduct are any less optimal than the sanctions for litigation conduct. And, without such evidence, nothing suggests that advice about the sanctions applicable to primary conduct is any more or less desirable than advice about the sanctions applicable to litigation conduct.

A more tailored approach for curbing those forms of advice that are likely to lead to undesirable consequences may be justifiable. But open-ended efforts to screen out such undesirable advice, such as that advocated by William Simon, are likely to face insuperable problems of overdeterrence. They are, in other words, likely to screen out too much desirable advice as well. The approach taken by current law, targeting only those categories of advice that further known crimes or frauds, better redresses the problem of underdeterred undesirable advice without excessively overdeterring desirable advice.

Finally, even when sanctions do not optimize behavior, it is not true that advice or knowledge about sanctions is generally undesirable. Sometimes the behavioral consequences will be undesirable, but other times they will be desirable. Absent more particular evidence about what exactly unadvised or ignorant parties would over- or underestimate, the overall behavioral effect of advice or knowledge about nonoptimal sanctions must be regarded as ambiguous. Given this behavioral ambiguity, the fairness considerations in favor of legal advice are often controlling. 